ANUARIO De Estudios Medievales

$51 / 1$, enero-junio de 2021, pp. 29-72

ISSN 0066-5061

https://doi.org/10.3989/aem.2021.51.1.02

\title{
REYES, OBISPOS Y PAPAS EN CASTILLA: EL PAPEL DE LOS PRELADOS EN LAS RELACIONES CON EL PAPADO (SIGLOS XIII Y XV)
}

\author{
KINGS, BISHOPS AND POPES IN CASTILE: THE ROLE OF PRELATES IN THE \\ RELATIONSHIP BETWEEN MONARCHY AND PAPACY $\left(13^{\text {th }}-15^{\text {th }}\right.$ CENTURIES)
}

ÓSCAR VILLARROEL GONZÁLEZ

Universidad Complutense de Madrid https://orcid.org/0000-0001-6221-5689

\begin{abstract}
Resumen: A lo largo del presente trabajo se analiza la presencia de laicos, eclesiásticos y, entre ellos, los prelados en las embajadas de la corona de Castilla a la Curia pontificia en los siglos bajomedievales. El objetivo principal es establecer un listado de enviados regios castellanos (analizando su composición, grado y formación) y el estudio concreto de los prelados. Con ello se busca profundizar en el conocimiento de las bases sobre las que se desarrollaron esas relaciones y, al tiempo, ofrecer un listado que facilite la investigación de su peso real en la transmisión artística y cultural con la presentación de una nómina de esos enviados.
\end{abstract}

Palabras clave: Castilla; diplomacia; embajador; Curia pontificia; siglos XIII-XV.

Abstract: In this paper, we analyse the presence of lay people and members of the clergy, including prelates, as ambassadors of Castilian kings in the papal Curia between the $13^{\text {th }}$ and $15^{\text {th }}$ centuries. The main goal is to establish a list of royal delegates (through a review of their composition, degrees and studies), with a special focus on prelates. This seeks to delve into the bases on which relationships were developed and, at the same time, facilitate an analysis of their real significance in artistic and cultural transmission with a record of royal delegates.

Keywords: Castile; diplomacy; ambassador; Roman Curia; $13^{\text {th }}-15^{\text {th }}$ centuries.

\section{SUMARIO}

1. Introducción.- 2. Las relaciones entre las monarquías y el papado en el periodo bajomedieval.- 3. Los diplomáticos en la Edad Media.- 4. Los eclesiásticos como diplomáticos.- 5. Los eclesiásticos, y prelados, como embajadores ante el papa.- 6 . La experiencia previa de los embajadores prelados.- 7. La formación.- 8. A modo de conclusión.- 9. Anexos.- 9.1. Anexo 1. Embajadores y enviados a Curia por los reyes de Castilla.- 9.2. Anexo 2. Repetición de misiones por los prelados.- 10 . Bibliografía citada.

Citation / Cómo citar este artículo: Villarroel González, Oscar (2021), Reyes, obispos y papas en Castilla: el papel de los prelados en las relaciones con el papado (siglos XIII y XV), "Anuario de Estudios Medievales" 51/1, pp. 29-72. https://doi.org/10.3989/aem.2021.51.1.02

Copyright: (C) 2021 CSIC. Este es un artículo de acceso abierto distribuido bajo los términos de la licencia de uso y distribución Creative Commons Reconocimiento 4.0 Internacional (CC BY 4.0). 


\section{INTRODUCCIÓN ${ }^{1}$}

Es un hecho casi comúnmente aceptado que, durante los siglos bajomedievales y por diversos avatares, los miembros del clero tuvieron en ocasiones un papel fundamental como emisarios entre el papado y las monarquías ${ }^{2}$. El primero seguía siendo una fuente inestimable de poder, como cabeza de la Iglesia, y era objeto de todo tipo de solicitudes que eran necesarias para las segundas. Estas, en pleno proceso de expansión de su poder, tenían en su política religiosa una gran cantidad de intereses: desde el control de los beneficios hasta la concesión de rentas eclesiásticas, pasando por intereses puramente devocionales ${ }^{3}$.

Esto, que ha sido objeto de análisis en diversas ocasiones ${ }^{4}$, nos lleva al hecho de que, con ello, a lo largo de los siglos XIII, XIV y XV, hubo una cierta cantidad de eclesiásticos que, al servicio del poder regio, viajaron por Europa y, en el caso de la Curia, especialmente a Italia. Así, dentro del marco monográfico en el que se desarrolla este trabajo, parece interesante el hecho de que pudiesen ser el origen de la extensión de influencias culturales de todo tipo, lo que incluye, obviamente, las artísticas ${ }^{5}$. Parece evidente que para poder analizar esa posible influencia es necesario conocer quiénes y cuándo fueron enviados. Y ese es el objetivo del presente trabajo: poder presentar un elenco de embajadores regios para que se pueda, posteriormente, comprobar esas posibles influencias. La cuestión que se nos planteaba es ¿cuántos y quiénes fueron los embajadores en el periodo bajomedieval castellano? Para ello se tuvieron en cuenta todos ellos, fuesen o no eclesiásticos y, posteriormente, fuesen o no prelados. El resultado se presenta en el anexo 1.

Sin duda, al contar con un listado (aunque este aún podamos considerarlo incompleto) se podría profundizar en el conocimiento de esas posibles influencias que recibieron o adquirieron en sus viajes y que luego pudieron aplicar en sus sedes (cuando eran prelados) o en las obras en las que interviniesen como mandatarios o mecenas. Fruto de aquel seminario al que fui ama-

\footnotetext{
${ }^{1}$ Abreviaturas utilizadas: $\mathrm{AAV}=$ Archivio Apostolico Vaticano; $\mathrm{ACB}=$ Archivo de la $\mathrm{Ca}-$ tedral de Burgos; ACDAlba = Archivo de la Casa Ducal de Alba; ACRV = Archivo de la Real Chancillería de Valladolid; ACS = Archivo de la Catedral de Salamanca; ACT = Archivo de la Catedral de Toledo; AGS = Archivo General de Simancas; AHNob = Archivo Histórico de la Nobleza; $\mathrm{ANF}=$ Archives nationales de France; $\mathrm{ASR}=$ Archivio di Stato di Roma; $\mathrm{BNF}=$ Bibliothèque nationale de France $; \mathrm{RA}=$ Registra Avenionensia; RAH $=$ Real Academia de la Historia; RL = Registra Lateranensia; RS = Registra Supplicationum; RV = Registra Vaticana.

${ }^{2}$ Nieto 1988, pp. 48-58; 1993a, pp. 290-309; Díaz 1987, 1988; Villarroel 2010a, 2013a; Moeglin, Péquignot 2017, p. 393.

${ }^{3}$ Nieto 1993 b, pp. 43-59; 1994, pp. 113-117.

${ }^{4}$ Un ejemplo clásico: Genet 1986.

${ }^{5}$ Esto ya fue planteado para los siglos XIV y XV por Nieto 2009.
} 
blemente invitado por la profesora Teijeira, es el presente trabajo que espera aportar alguna respuesta 6 .

Trazaremos, por ello, un rápido repaso a las relaciones de las monarquías con el papado en el periodo bajomedieval, el peso de la diplomacia en esas relaciones, la participación de los eclesiásticos en ella y la presencia real de los prelados. Eso nos permitirá abordar el peso específico que pudieron tener, además de identificar a aquellos que, en nuestro conocimiento actual, sabemos que estuvieron en la Curia como representantes de la monarquía castellana. Por último, a la luz de ello, trataremos de analizar brevemente el perfil de esos prelados embajadores, así como las circunstancias de sus misiones, dado que un análisis completo de todas y cada una, así como de las razones de la elección de cada enviado, requeriría mucho más espacio del aquí concedido. Queremos indicar, además, que intencionadamente se corta el estudio antes del ascenso al poder de los Reyes Católicos, dado que ello duplicaría, al menos, el presente trabajo (tanto en fuentes como en historiografía -con los magníficos trabajos de Fernández de Córdova como buen ejemplo-).

\section{LAS RELACIONES ENTRE LAS MONARQUÍAS Y EL PAPADO EN EL PERIODO BAJOMEDIEVAL}

Como se ha comentado, es de sobra conocido el hecho de que el poder que el pontificado tenía sobre la Iglesia occidental le convertía en un interlocutor para las monarquías que crecían en esos mismos siglos. El control beneficial que el papado de Aviñón impuso sobre el conjunto de las iglesias occidentales era una de las principales razones, pero también su capacidad para conceder a los reyes y príncipes europeos las prerrogativas religiosas y las rentas eclesiásticas que podían necesitar ${ }^{7}$.

El pontificado se caracterizó por la imposición de un fuerte centralismo en la Iglesia. La reserva de beneficios, mayores y menores, fue uno de sus resultados. El papa se arrogaba el poder de otorgar cualquier beneficio que se hubiese reservado de eclesiásticos fallecidos en la Curia o cerca de ella ${ }^{8}$. De esta forma, los papas tenían un importante poder a la hora de entregar algunos de los más preciados puestos eclesiásticos, como eran las diversas prelaturas. Con ello, las monarquías presentaban ante el papa sus propuestas para la elección de tal o cual persona. No era una novedad, los reyes solo variaban el

\footnotetext{
${ }^{6}$ Arte y poder episcopal en Castilla siglos XIV y XV, Universidad de León, 22 y 23 de noviembre de 2018.

${ }^{7}$ Gaudemet 1986, pp. 279-293; Nieto 1993b, pp. 343-379.

${ }^{8}$ Williman 1988, pp. 1-37; Azcona 1960, pp. 63-64; Villarroel 2003b, pp. 262-263.
} 
objeto de atención: del cabildo de turno al papa; en Castilla estaba asentada la tradición de que los reyes debían ser informados y escuchados a la hora de una nueva elección episcopal ${ }^{9}$.

El papado, además, ostentaba la cabeza del poder religioso y, como tal, podía ser autor de concesiones de ese tipo, que eran susceptibles de tener un valor simbólico fundamental para los poderes regios. Unos poderes que eran claramente conscientes de la capacidad de transmisión de mensajes políticos que tenían las imágenes simbólico-religiosas ${ }^{10}$.

Y, por último, los papas ejercían también un importante poder económico dados los emolumentos que recibían de toda la cristiandad ${ }^{11}$. Como cabeza de la Iglesia podía conceder la autoridad para obtener parte de las rentas eclesiásticas por diversos motivos ${ }^{12}$. En el caso de los reinos peninsulares fue habitual y tradicional la excusa de la lucha contra el Islam, que hizo que, de diversas formas, rentas eclesiásticas acabasen siendo utilizadas por las monarquías ${ }^{13}$.

Estas relaciones, sin embargo, no siempre fueron cordiales, dado que el pontificado, a la par que extendía su control y sus redes fiscales, pasaba a convertirse en un poder externo que intervenía sobre parte de un reino. Una parte tan importante en el periodo medieval como era su Iglesia. Las reservas beneficiales, que fueron generalizándose, hicieron que las monarquías viesen, en ocasiones, en ese intervencionismo pontificio una suerte de agente extraño que causaba determinados problemas: el absentismo de los beneficiados (fuesen prelados o no) que obtenían en la Curia sus cargos y en muchas ocasiones nunca se personaban en el lugar del que cobraban sus beneficios (con la anuencia pontificia). De este modo, la presencia de clérigos extranjeros era visto como algo pernicioso por los reyes. Y esto era así no solo por el absentismo, sino porque, además, suponía una auténtica fuga de capitales, puesto que sus rentas eran directamente derivadas allí donde residían, en muchas ocasiones la Curia ${ }^{14}$.

Por todo ello, las relaciones entre monarquía y pontificado, fueron muy habituales a lo largo de los siglos XIII, XIV y XV, si bien de formas cambiantes. Efectivamente, la historiografía ha mostrado cómo a lo largo del siglo $\mathrm{XIV}$, y coincidiendo con el papado de Aviñón, nos encontramos su predominio en esas relaciones. La extensión de las reservas, el incremento de las finanzas

\footnotetext{
${ }^{9}$ Ibidem.

${ }^{10}$ Nieto 1993a, pp. 83-85, 141-144, 183-199; 1993b, pp. 223 y ss.

${ }^{11}$ Favier 1966; Weiß 2016, pp. 220-238.

${ }^{12}$ Nieto 1993b, pp. 311-341.

${ }^{13}$ Morelló 2013. Para el caso castellano: Villarroel 2013b. Cuando no todo tipo de favores, ya llamó la atención sobre ello Linehan 1975, p. 93.

${ }^{14}$ Nieto 1993b, pp. 344-356.
} 
pontificias por todo el occidente... sin duda fueron unas de sus principales características, que ayudaron, no poco, a la extensión de la imagen de la curia aviñonesa como una rapaz en busca de rentas ${ }^{15}$.

Una vez iniciado el Cisma de Occidente, si bien aparentemente la relación no había variado, y si bien los papas buscaban ejercer la misma autoridad sobre los territorios que les obedecían, lo cierto es que la situación tendió rápidamente al cambio. Ahora eran los papas los que buscaban el apoyo de las respectivas monarquías. Necesitaban el sostén de los poderes laicos y se inició así una política de concesiones a los reyes de aquellas cuestiones eclesiásticas que podían serles de interés (lo que incluía los principales beneficios de sus reinos).

El Cisma fue, de este modo, un elemento que agilizó las relaciones entre papado y monarquías, dado que el envío de embajadores para la consecución de tal o cual gracia fue más habitual, o al menos obtenían éxito en mayor número de ocasiones. La generalización del sistema de los rótulos es un buen ejemplo: el envío de listas (más o menos extensas) de solicitudes de beneficios para diversas personas, que el papa de turno aceptaba con su fiat. Con ello se establecía una nueva tónica, en la que el papado estaba mucho más abierto a las peticiones. Esto culminó con el cierre del Cisma, en el Concilio de Constanza, y lo que se ha dado en llamar el régimen concordatario que allí se inició ${ }^{16}$.

La cuestión que se planteaba en un inicio, dentro del monográfico, era qué papel jugaron en esas relaciones los prelados. Parece lógico esperar una importante presencia, por su relación directa con el pontificado, de la cual podía beneficiarse la monarquía utilizándolos como diplomáticos. Para ello, obviamente, había que analizar el conjunto de los enviados regios castellanos y por ello se presenta el anexo completo. Para abordar tal cuestión, lógicamente, hemos de mostrar en un primer momento la situación de la diplomacia en el periodo bajomedieval, así como la inserción de los eclesiásticos en ella, para posteriormente analizar quiénes fueron los enviados castellanos en la Curia (laicos o eclesiásticos y, dentro de estos, prelados o no).

\section{LOS DIPLOMÁticos EN LA EDAD MEDIA}

Durante mucho tiempo se ha hablado de la teórica y típica composición tripartita de una embajada medieval. Esta estaría compuesta, básicamente, por un eclesiástico, un noble y un oficial ${ }^{17}$. Esta visión, que parte de análisis

\footnotetext{
${ }^{15}$ Tuchman, 2014, pp. 46-47.

${ }^{16}$ Nieto 1994 , pp. 117 y ss.

${ }^{17}$ Autrand 1999, pp. 27-45; Díaz 1987, p. 138.
} 
decimonónicos, puede ser puesta en duda como norma general ${ }^{18}$. La realidad nos muestra una amplia variedad porque, aunque podemos encontrarla en ocasiones $^{19}$, son mucho más habituales composiciones distintas ${ }^{20}$. Si analizamos el caso castellano, en concreto, un rápido vistazo a un elenco de embajadores nos muestra más la variedad que esta supuesta norma ${ }^{21}$.

Otro aspecto para tener en cuenta serían las razones para ese desempeño diplomático. ¿Lo eran por ser eclesiásticos? No se puede dar una respuesta general, ni afirmativa ni negativa. Aunque parece obvio que la confianza estaba en la base de cualquier nombramiento, las razones en el fondo podían ser múltiples a la hora de elegir un enviado, desde las puramente personales (la seguridad de un fiel servidor), hasta otras más pragmáticas (su conocimiento del ámbito en el que se negociaba, bien fuese la materia o el destinatario de la embajada). El caso de los principales diplomáticos del periodo, al menos en el caso castellano, así nos lo demuestra. Los dos embajadores que más participaron en embajadas entre finales del XIV y las primeras décadas del XV fueron Pero López de Ayala y Fernando de Illescas, uno canciller mayor y el otro confesor regio ${ }^{22}$. Parece indudable, en el estado actual de la investigación, que algunos embajadores estaban especializados en ámbitos o temáticas concretas. Así, por indicar algunos ejemplos conocidos, Juan Hurtado de Mendoza lo estaba en tratar con la monarquía aragonesa a principios del siglo XV, al igual que Diego Bedán ${ }^{23}$ o Gonzalo Moro con el ámbito inglés ${ }^{24}$. E, incluso, dentro de los enviados a la Curia, y remontándonos al XIII, aparece la figura de Rodolfo de Podio Bonizzi (o Poggibonsi) que participó en un total de cuatro misiones entre 1263 y $1273^{25}$. El hecho de que fuese antiguo notario imperial (de Federico II, Conrado IV y Manfredo ${ }^{26}$ ), así como su conocimiento de las formas y fórmulas del ars dictamnis imperante en la Curia, fueron razones fundamentales para su elección ${ }^{27}$.

De este modo, en ocasiones, la experiencia podía llegar a ser un punto muy favorable a la hora de elegir un embajador y solía ir en paralelo a la confianza regia. Hay ejemplos que cumplen estos parámetros. Así, por ejem-

${ }^{18}$ Villarroel 2019a, pp. 2-3; Moeglin, Péquignot 2017, pp. 378 y ss.

${ }^{19}$ Autrand 1999; Díaz 1987; Beceiro 1995-1996.

${ }^{20}$ Moeglin, Péquignot 2017, pp. 378-380.

${ }^{21}$ Villarroel 2019a, pp. 18-29.

${ }^{22}$ Villarroel 2019b, pp. 144-146.

${ }^{23}$ Villarroel 2020, pp. 574-575.

${ }^{24}$ Aún hay mucho por investigar de este personaje, sucintamente en: Santos 1935.

${ }^{25}$ Véase anexo 1.

${ }^{26}$ Schaller 1958, p. 281; Delle Donne 2004, pp. 108-109. Tampoco es baladí, como indicó Grevin (2020, p. 22), que fuese toscano.

${ }^{27}$ Grevin 2008, p. 278. 
plo, Álvaro Núñez de Isorna, uno de los pocos prelados embajador en Roma, fue antes servidor regio. Después de mostrar su valía en la negociación en conflictos internos fue enviado a la Curia romana en una importante misión en 1421, para posteriormente acudir también como delegado regio al Concilio de Basilea en $1434^{28}$. Es, también, ejemplo de cómo esa experiencia no garantizaba un rol principal en la misión: en esa última embajada ante el Concilio sería Alonso de Cartagena, vinculado al humanismo ${ }^{29}$, el auténtico ideólogo ${ }^{30}$.

Por último, había un tercer elemento que podía tener peso en el nombramiento: los conocimientos propios que facilitasen la misión a desempeñar. ¿Los idiomas influían en tal nombramiento? Por desgracia eso es algo que, en condiciones normales, es muy difícil llegar a saber, dado que apenas conocemos los estudios de muchos de los embajadores y menos aún los idiomas que eran capaces de hablar ${ }^{31}$. En algunos casos podemos pensar que eran razón para ello: cuando vemos a algún embajador repetir misiones a ámbitos donde no se utilizaba el castellano como lengua diplomática. Esto, en el caso que nos ocupa, nos lleva a pensar que los eclesiásticos, si tenían un buen dominio del latín, podían ser buenos agentes para su servicio ante el pontificado. Si bien no siempre era la lengua franca en la diplomacia, como se está apreciando por los estudios recientes ${ }^{32}$, qué duda cabe que en la Curia sí tenía un peso fundamental, dado que era la lengua de trabajo de la cancillería y la administración. Así, por ejemplo, sabemos que Juan Martínez Contreras transmitió, en esa lengua, a quien iba a defender su caso ante el consistorio, las órdenes detalladas de lo que debía decir ${ }^{33}$. Pese a ello, tal vez hubiese que tener en cuenta la posibilidad de que el italiano tuviese más o menos peso en las negociaciones orales, especialmente cuando las curias estaban dominadas por italianos, o el provenzal mientras el papado estuvo en Aviñón.

En cuanto al tipo de estudios, parece lógico pensar que el derecho canónico debía ser fundamental para cualquier negociación con el papado, especialmente al tratarse sobre derechos y rentas de la Iglesia, así como sobre política beneficial. Otra cuestión es qué formación fue la que primó realmente. En el fondo nos encontramos una amplia variedad, aunque, como ocurre con la generalidad de los embajadores o servidores en el ámbito diplomático, de la mayoría de los enviados ante la Curia no tenemos datos sobre sus estudios,

${ }^{28}$ Villarroel 2017, pp. 269-278.

${ }^{29}$ González, Saquero 2010.

${ }^{30}$ Fernández 2002, pp. 133-208

${ }^{31}$ Sobre la formación de los embajadores véase: Villarroel 2018, pp. 126-131.

${ }^{32}$ Moeglin, Péquignot 2017, pp. 112-126.

${ }^{33}$ ACT, doc. A. 8. L 1. 1. a; copia en BNE, ms. 13018, ff. 149 y ss.; Villarroel 2016c, pp. 188-189. 
como se ha mostrado recientemente para el ámbito específico de la Castilla de la primera mitad del siglo $\mathrm{XV}^{34}$.

\section{LOS ECLESIÁSTICOS COMO DIPLOMÁTICOS}

Parece obvio decir que los eclesiásticos tuvieron un papel relevante en la diplomacia a lo largo del periodo medieval. Los estudios sobre la diplomacia medieval los tienen por objeto en muchas ocasiones. En el caso castellano, incluso, ha habido algún trabajo analizando sus labores, así como su personalidad ${ }^{35}$. Eso nos permite conocer el perfil básico de un embajador eclesiástico en aquellos momentos.

Ciertamente el caso de la representación ante la Curia nos llevaría a plantear como hipótesis que la condición de eclesiástico podría ser casi un requisito para ejercer tal función. Sin embargo, los datos demuestran que, de forma general, no era así. Al menos entre los siglos XIV y XV eran abundantes, pero había los suficientes enviados laicos como para que la hipótesis no sea sostenible.

Efectivamente, fuese por su formación o por su condición, lo cierto es que hubo laicos que desempeñaron importantes papeles en esas misiones, aunque cuantitativamente los eclesiásticos fuesen más y tuviesen un relevante papel, incluido el simbólico (donde los prelados estaban llamados a tener mayor peso). Pero eso no quiere decir que fuese una condición sine qua non. Entre mediados del siglo XIII y finales del XV se ha podido observar cómo de los casi 500 embajadores castellanos, 266 eran clérigos con beneficios de cierta importancia y que actuaban como tales (dignidades, canónigos, prelados...) ${ }^{36}$. Frente a ellos, había 92 nobles y 106 oficiales (dentro de los cuales podía haber también eclesiásticos, pero que eran mencionados como oficiales en primer lugar). Del resto, 35, no sabemos su condición. Así pues, los miembros del clero eran un número ciertamente importante, que superaba la mitad de los embajadores; pero es obvio que no era necesario serlo para actuar en diplomacia.

Pero ¿y la prelatura? ¿Era un valor añadido a la hora de desempeñar una misión ante el pontífice? El hecho de que los prelados tuviesen que atender obligaciones religiosas en la Curia (en el siglo XIII se documentó un cierto movimiento por las deudas contraídas ${ }^{37}$, pero es difícil estimar cómo eso pue-

\footnotetext{
${ }^{34}$ Villarroel 2018.

${ }^{35}$ Villarroel 2010a, 2013a, 2017, 2019a, 2019b.

${ }^{36}$ Véase el elenco en Villarroel 2018, pp. 134-144. Hoy día la cifra de nuestro conocimiento se eleva a 470 y 245 .

${ }^{37}$ Linehan 1975, pp. 117-123.
} 
de extenderse al conjunto del periodo bajomedieval), podía ser aprovechado por la monarquía para que actuasen como sus propios representantes. ¿Supuso eso una abundante presencia? Tampoco. De hecho, es relevante el hecho de que los prelados supongan, en cierto modo, una minoría. De esos 266 eclesiásticos que fueron embajadores, el $5 \%$ eran arzobispos, el $29 \%$ obispos, el $39 \%$ dignidades, el $13 \%$ canónigos y beneficiados menores y del $14 \%$ no conocemos su condición ${ }^{38}$. Es decir, en el fondo los prelados eran apenas un $19 \%$ de esos 500 embajadores castellanos mencionados. Obviamente había variaciones por épocas, como veremos posteriormente.

Así, es interesante apreciar cómo, si en el siglo XIII fueron muy abundantes, su número irá en descenso rápidamente. Durante el XIV bajó drásticamente, en 19 misiones enviadas solo hay 4 obispos. Y posteriormente se produjo el incremento de las dignidades hasta convertirse en el embajador eclesiástico prototípico en el siglo $\mathrm{XV}^{39}$.

Otro punto a tener en cuenta sería la presencia de eclesiásticos castellanos en la Curia sin ser embajadores. Hace tiempo que se mostró cómo los nacionales de un reino podían defender los intereses o peticiones de su rey ${ }^{40}$, o al menos colaborar con sus enviados (aunque a veces fuesen mal vistos ${ }^{41}$ ). Sin embargo, no serán tenidos en cuenta aquí, pues su estudio, dentro de los dos siglos y medio que se abarca, supondría un trabajo independiente y, posiblemente, más amplio que el actual.

\section{LOS ECLESIÁSTICOS, Y PRELADOS, COMO EMBAJADORES ANTE EL PAPA}

De esta forma, como se ha podido observar, existía una presencia habitual de representantes castellanos en la Curia pontificia desde el siglo XIII. Ahora bien, ¿cuántos de entre los que podemos considerar que acudieron a Aviñón o Roma como embajadores regios eran eclesiásticos?, y, de entre ellos, ¿cuántos prelados? Porque algunos, como hemos visto, fueron elevados al episcopado por el papa mientras estaban a su servicio, con lo cual no eran embajadores regios (o no eran alzados por ello). Como veremos, en cuanto al número de eclesiásticos, se mantienen los porcentajes que se han podido apreciar a nivel general. Además, como se ha dicho con anterioridad, los prelados no fueron durante todo el periodo bajomedieval el embajador prototípico ante el papado.

\footnotetext{
${ }^{38}$ Villarroel 2018, pp. 134-144.

${ }^{39}$ Villarroel 2010a, pp. 816-819.

${ }^{40}$ Linehan 1980 para el siglo XIII; para el XIV y el XV: Nieto 1993b, pp. 44-59; Villarroel 2010b, pp. 31-32, 112-124; en el caso inglés Bombi 2017, pp. 76-101.

${ }^{41}$ Linehan 1975, pp. 221-223.
} 
Si nos atenemos a los que se han localizado actualmente (y con la consciencia de que es un listado incompleto), nos encontramos con datos muy interesantes ${ }^{42}$. De 150 enviados regios ante los papas desde 1251 hasta 1474 , 104, al menos, fueron eclesiásticos (hay algún oficial regio -y que era mencionado como tal- que también era eclesiástico, lo que eleva la suma a 106). Dentro de los clérigos, los prelados (el grupo que nos interesa) solo fueron 34, frente a un total de 47 dignidades (contando los tres oficiales que eran arcedianos), a lo que habría que sumar 5 canónigos y otros cargos menores (cantor, porcionario, arcipreste...), además de 15 de los que no conocemos su cargo. Es decir, nos encontramos con una mayor presencia de dignidades, aunque tras ellos había un número ciertamente relevante de prelados que alcanzaba el $22 \%$ del total (y el 32,1\% entre los eclesiásticos). Es decir, los prelados no eran la figura típica de la diplomacia regia ante el papa. Pese a esto, ciertamente, el obispo es la categoría más abundante, con 30 embajadores; pero sin duda eso se debe a la mayor variedad en los cargos de las dignidades (arcedianos, maestrescuelas, deanes...), así como entre los laicos (nobles de variado título, oficiales regios muy diversos...). Así pues, en general, estas cifras se corresponden con la visión presentada por análisis anteriores sobre los embajadores eclesiásticos en periodos concretos del siglo $\mathrm{XV}^{43}$.

Pero hay que tener en cuenta dos matices muy importantes. Por un lado, la extraordinaria concentración de prelados en la parte del siglo XIII analizada, y en especial, en el reinado de Alfonso X. En concreto, en la segunda mitad del siglo XIII hubo un total de 20 (un arzobispo y 19 obispos). Es decir, un $60 \%$ de los enviados de esta categoría como embajadores a la Curia pontificia se concentran en los primeros cincuenta años del análisis. Pero, además, durante el reinado de Alfonso X fueron 19 (un arzobispo y 18 obispos). Así el $57 \%$ se concentra solo en el reinado de este monarca. Como vemos, los datos son realmente relevantes.

El segundo matiz es la tasa de equivalencia entre el número de prelados y el de dignidades, que veremos varía notablemente con el paso del tiempo, obviamente por el reparto desigual ya mencionado. Eso hace que haya momentos puntuales en los que hay excepciones y los prelados sí tenían un especial peso. Así, en el siglo XIII nos encontramos un total de 20 prelados, frente a 12 dignidades y otros 4 eclesiásticos de diverso tipo (o de los que no sabemos nada). En el XIV las cifras son 4, 6 y 6; y en el XV, 10, 26, 19 (gráfico 1$)^{44}$.

\footnotetext{
${ }^{42}$ Véase el anexo 1.

${ }^{43}$ Villarroel 2010b.

${ }^{44}$ En estas cifras sí se incluyen los oficiales que eran eclesiásticos pero se presentan como oficiales regios, de ahí que la suma total sean 105 casos.
} 


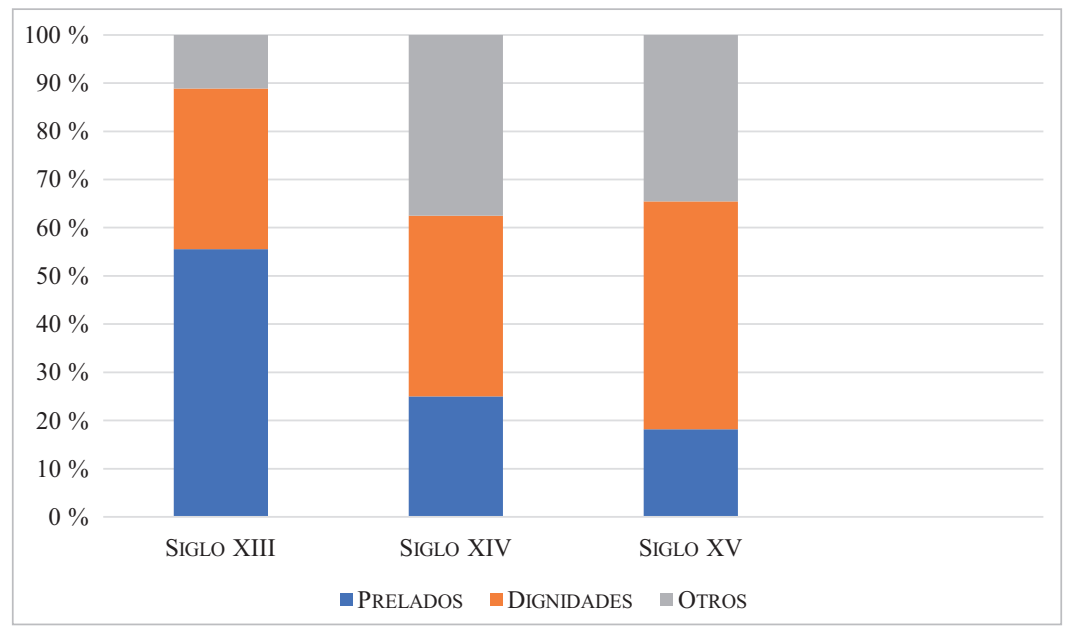

Gráfico 1. Embajadores eclesiásticos en Curia en proporción a su posición en la jerarquía

Los cambios son notables de un siglo a otro, pero nos permiten apreciar ciertas tendencias. En primer lugar, el descenso comparativo del número de prelados frente a los otros grupos y el ascenso de las dignidades. Es llamativa la situación de la segunda mitad del siglo XIII. Lo primero que llama la atención es lo desequilibrado del número de prelados que, comparativamente, actuaron como embajadores en el siglo XIII. Sin duda el llamado "fecho del Imperio" supone un gran elemento distorsionador de esa presencia ${ }^{45}$.

Las razones de por qué Alfonso consideró más adecuado el envío de obispos para tratar esta cuestión ante el papa, frente a la posición de sus sucesores (que recurrieron más a otro tipo de eclesiásticos) son difíciles de calibrar. La implicación de la Iglesia castellana, y personal de algunos prelados del entorno regio, fue realmente relevante ${ }^{46}$. Parece obvio que hay un claro componente simbólico, buscando el apoyo de la prelatura y de la Iglesia ante el papa. Parece plausible pensar que el gibelinismo con el que el rey había vestido su aspiración al trono imperial podía tener mucho que ver ${ }^{47}$. La propia concepción del poder y el programa político del monarca así lo muestran ${ }^{48}$. Una aspiración basada en la superioridad del poder temporal debía parecer mucho más defendible ante el papa si se realizaba por prelados que obedecían

\footnotetext{
${ }^{45}$ Nieto 1988 , pp. 54-60.

${ }^{46}$ Ibidem, p. 56.

${ }^{47}$ Ayala 1987, pp. $7-8$

${ }^{48}$ Ayala 2014-2015, pp. 41-42.
} 
a su rey/emperador. Así, un poder que se mostraba bajo esquemas de sacralidad y como vicario divino, sin duda había de tener en los prelados a sus principales agentes como interlocutores con un poder religioso ${ }^{49}$. De hecho, esas misiones episcopales no serían sino el reflejo del deber de obediencia y fidelidad de los prelados del reino al monarca (concebido con tal superioridad) ${ }^{50}$.

Pero es difícil explicar la razón de que, después, el número de prelados decayese y aumentase, a la vez, el grupo de las dignidades. Estas, además, mantienen una presencia muy semejante (en porcentaje) entre los siglos XIV y XV. El siglo XIV puede y debe ser revisado, en busca de más misiones de las que hay localizadas, puesto que tal vez haya diferencias con el siglo XV que se nos escapen con un muestreo que apenas puede ser considerado en una estadística. Sin embargo, el siglo XV parece responder a la búsqueda de unos servidores regios formados y no pertenecientes al episcopado en su mayor parte. Desde luego, así se ha visto para el reinado de Juan II de Castilla ${ }^{51}$.

En el reinado de Enrique IV se ha indicado, últimamente, un incremento de la presencia de prelados (hablando, incluso, de predominio), junto al paulatino (y tal vez adelantado) incremento de los laicos y nobles como embajadores $^{52}$. Sin embargo, a la hora de analizar los prelados, hemos de tener muy en cuenta cuándo acceden a tal condición. Muchos de los enviados a la Curia por este rey no lo eran en el momento en que fueron remitidos allí. Con lo cual, no pueden ser cuantificados como tales. Así, si observamos el anexo 1, vemos que con Enrique IV solo 5 fueron enviados mientras eran obispos, frente a 11 dignidades (desde chantre hasta deán). De este modo, se mantiene la relación cuantitativa que se había desarrollado a lo largo del reinado de Juan II.

Es obvio que, a lo largo de los algo más de dos siglos analizados, hubo prelados de gran relieve entre los enviados a la Curia. Un rápido repaso a la nómina así nos lo muestra: Gil de Albornoz, Rodrigo Sánchez de Arévalo, Alfonso de Cartagena, Álvaro Núñez de Isorna, Alfonso de Ejea, Alfonso de Argüello, Juan Alfonso de Mella... Ciertamente nos encontramos entre ellos a algunos personajes con una larguísima trayectoria y actuaciones ciertamente relevantes. Unos como embajadores regios, otros como miembros de la Curia, y alguno destacando en el mundo humanista o prehumanista. Sin embargo, más allá de los análisis personales que se pueden realizar, y sobre algunos de los cuáles ya se han realizado, tanto desde la Historia como desde la Historia del Arte y de la Historia de la Cultura, cabe aquí plantear un estudio grupal y de tipo prosopográfico que nos permita plantear alguna respuesta de tipo general.

\footnotetext{
${ }^{49}$ Fernández-Viagas 2017, passim.

${ }^{50}$ Ayala 2014-2015, p. 43.

${ }^{51}$ Villarroel 2010a, pp. 816-819.

${ }^{52}$ González 2019, pp. 113 y 111-112, respectivamente.
} 


\section{LA EXPERIENCIA PREVIA DE LOS EMBAJADORES PRELADOS}

Como se sabe, en los reinos occidentales eran los monarcas (o el poder remitente) los que elegían a sus embajadores ${ }^{53}$. De forma invariable, es la proximidad y la confianza lo que hacía que una persona fuese nombrada como tal ${ }^{54}$. Sin embargo, un elemento que se está mostrando, en ocasiones, como fundamental a la hora de la elección de estos delegados es la experiencia que pudiesen tener. En los últimos años, se ha podido apreciar que el embajador medieval, visto de una forma general, no repetía su misión y solo desempeñaba ese papel en una ocasión ${ }^{55}$. Pero es cierto que algunos de ellos sí lo hicieron e, incluso, algunos acabaron siéndolo de forma muy asidua y en múltiples misiones. Efectivamente, cada vez nos encontramos con más ejemplos de embajadores que tras llevar a cabo con éxito su embajada eran elegidos de nuevo para desempeñar otras $^{56}$. Pero López de Ayala era el paradigma, pero poco a poco se van desvelando otros embajadores que tuvieron tanta presencia, o incluso más, que él en el ámbito diplomático. Además, esta experiencia podía variar entre una general en el campo de la diplomacia (es decir, haber participado anteriormente en misiones), o bien una mucho más cercana al objeto de la misión.

En este caso, ¿encontramos veteranía entre los prelados enviados a Curia como embajadores? Hay una gran variedad. Desde algunos con un currículum notable a otros que nunca habían participado en diplomacia. Así, por ejemplo, de entre los prelados, solo participaron en más misiones 10 de ellos: Rodrigo Sánchez de Arévalo (el que en más ocasiones lo hizo: un total de 7), Fortún Velázquez de Cuéllar (en cuatro ocasiones), Martín Fernández (que podría ser en tres o cuatro si el prelado de 1267 fuese él mismo), Alfonso de Argüello, García Pérez, Alfonso de Ejea, Álvaro Núñez de Isorna (los tres en tres ocasiones), Aymar, Domingo Suárez, Frédulo Pascual y Sancho de Rojas (todos ellos solo actuaron dos veces). Y, de hecho, en la Curia y como prelados, solo repitieron misión Alfonso de Argüello, Alfonso de Ejea, Aymar, Martín Fernández y García Pérez en dos ocasiones, y Rodrigo Sánchez de Arévalo en tres (Fortún Velázquez de Cuéllar acudió una primera vez siendo arcediano).

Un caso un tanto especial es el obispo Aymar, o Ademar. Este fue obispo electo de Ávila y enviado a la Curia en 1271 y en 1274. Este prelado ha sido considerado como dominico afecto a la monarquía y buen servidor de

\footnotetext{
${ }^{53}$ Moeglin, Péquignot 2017, p. 375.

${ }^{54}$ Ibidem, p. 389.

${ }_{55}^{5}$ Villarroel 2011, pp. 130-133; 2010a, pp. 818-819; Moeglin, Péquignot 2017, p. 411.

${ }^{56}$ Por ejemplo, tres casos distintos: Villarroel 2016c, 2017, 2019b. El caso de Felipe de Malla: García 2021; Pedretti 2012; Bofarull 1882.
} 
las causas de Alfonso X y gran privado del monarca ${ }^{57}$. Sin duda, dentro de la política del rey de presentar sus aspiraciones de superioridad, un obispo afecto era el mejor embajador. Sin embargo, como se puede ver en el anexo, se duda sobre su condición episcopal. La bibliografía del XVIII lo menciona como obispo cuando fue embajador ${ }^{58}$. Sin embargo, hay dudas sobre cuándo pasó a ocupar tal sede como electo. La documentación solo lo muestra claramente desde $1281^{59}$. Lo cierto es que la pontificia, de momento, no le menciona como tal en las fechas de su misión (de hecho, en 1272, por ejemplo, solo indica de él frater Ademarus, de Ordinem Predicatorum ${ }^{60}$ ).

Además, como se ha dicho, hay que tener en cuenta los prelados que tuvieron otra experiencia diplomática. Alfonso de Ejea actuó una vez ante el rey de Francia, muy posiblemente en la misma misión que le llevó ante el papa por primera vez ${ }^{61}$. Álvaro Núñez de Isorna fue embajador ante el Concilio de Basilea ${ }^{62}$, pero la misión en la Corte pontificia fue la primera ${ }^{63}$. Fortún Velázquez de Cuéllar es uno de los que más misiones tuvo fuera de ella, dos en total, primero actuó ante la Curia en $1443^{64}$, para luego ser embajador dos veces ante el rey francés ${ }^{65}$, y acabó siendo enviado de nuevo ante el papa, ya Pío II, y en el Concilio de Mantua ${ }^{66}$. Juan Martínez Contreras lo fue dos veces más, pero en ambos casos tras su embajada en Roma: en el Concilio de Siena y en la frontera aragonesa de 1430 a $1433^{67}$. Martín Fernández, obispo de León, es uno de los que más veces repitió ante el papa: cuatro veces si contamos la de 1267. No deja de ser interesante que, aparentemente, todas sus labores se desarrollasen allí68. García Pérez, obispo de Silves muerto en misión en 1267, había sido previamente embajador en el Imperio -y en el tránsito, tal vez, en Francia- ${ }^{69}$, y luego actuó dos veces en Curia ${ }^{70}$. Pascual, el obispo de Jaén, tuvo una embajada dúplice, pues además de acudir ante el papa visitó previa-

${ }^{57}$ Ayala 2014-2015, pp. 67 y 60, respectivamente.

${ }^{58}$ Risco 1794, pp. 201-203.

${ }^{59}$ González 2004, p. 410; Ayala 2014-2015, p. 67.

${ }^{60}$ Domínguez 1997, doc. 35.

${ }^{61}$ Daumet 1898, p. 60 y anexo 41; ANF, J603, n. ${ }^{\circ} 69$.

${ }^{62}$ Villarroel 2017, pp. 276-277.

${ }^{63}$ Villarroel 2016a, pp. 789-792; 2017, pp. 275-276.

${ }^{64} \mathrm{AAV}, \mathrm{RV}, 367$, f. 165r.

${ }^{65}$ Daumet 1898, p. 94; Palencia, Gesta hispaniensia, vol. I, p. 101. Para la segunda: Daumet 1898, p. 97 y anexo 66; BNF, ms. lat. 5956, ff. 221-222.

${ }^{66}$ Meserve, Simonetta 2004, vol. II, pp. 282-283; González 2019, p. 110.

${ }^{67}$ Villarroel 2016c.

${ }^{68}$ Véanse datos en el anexo 1.

${ }^{69}$ Daumet 1913, p. 10 y pieza 11; ANF, J600, n. ${ }^{\circ} 18$.

${ }^{70}$ Domínguez 2007, pp. 118-119; Rodríguez 1981, pp. 99-100; Alvira 2021, pp. 9-96. 
mente al rey de Aragón ${ }^{71}$. Sancho, el infante y arzobispo de Toledo, ya tenía experiencia previa, pues tuvo otra dúplice ante Francia e Inglaterra ${ }^{72}$. Sancho de Rojas, obispo de Córdoba, tuvo una en la Curia y otra ante el Concilio de Siena $^{73}$, pero además fue embajador ante Inglaterra y Navarra ${ }^{74}$. Por último, Rodrigo Sánchez de Arévalo tuvo su primera misión ante el emperador en 1438 junto a Alfonso de Cartagena ${ }^{75}$, donde regresó en $1442^{76}$; sin embargo, su principal campo de actuación sería la Curia con sus cinco embajadas y su estancia en Roma, donde acudió por primera vez en $1441^{77}$.

Como vemos, es un elenco muy variado a lo largo del tiempo el de los prelados que tuvieron algún otro tipo de experiencia diplomática. Algunos la tuvieron de forma previa, pero otros de forma posterior, de modo que no puede ser tomado como un hecho que justifique su elección para el desarrollo de la misión ante el papa de forma general. Solo en algunos casos podríamos considerar que sí parece evidente, especialmente cuando se repiten en la $\mathrm{Cu}$ ria, como el caso de Sánchez de Arévalo.

\section{LA FORMACIÓN}

Es de todos sabido lo importante que fue la formación a lo largo del periodo pleno y bajomedieval. Para muchos fue lo que les permitió el ascenso social y pertenecer a una parte más acomodada de la sociedad ${ }^{78}$. Esa gente dotada de estudios protagonizó un notable ascenso a lo largo de los siglos de este periodo, pasando a formar parte de los aparatos de las monarquías, siendo mencionados cada vez con mayor asiduidad ${ }^{79}$. Sin embargo, una cosa es que las fuentes mencionen más a los letrados o a los que tenían estudios universitarios y otra es que conozcamos perfectamente la formación de laicos, eclesiásticos, prelados, embajadores o cualquier otro tipo de servidor regio a lo largo del periodo medieval. Habitualmente, y a nivel general, tenemos datos solo de una parte reducida de ellos ${ }^{80}$. Indudablemente, conocemos mucho sobre los estudios y su importancia en el servicio regio y en algunos ca-

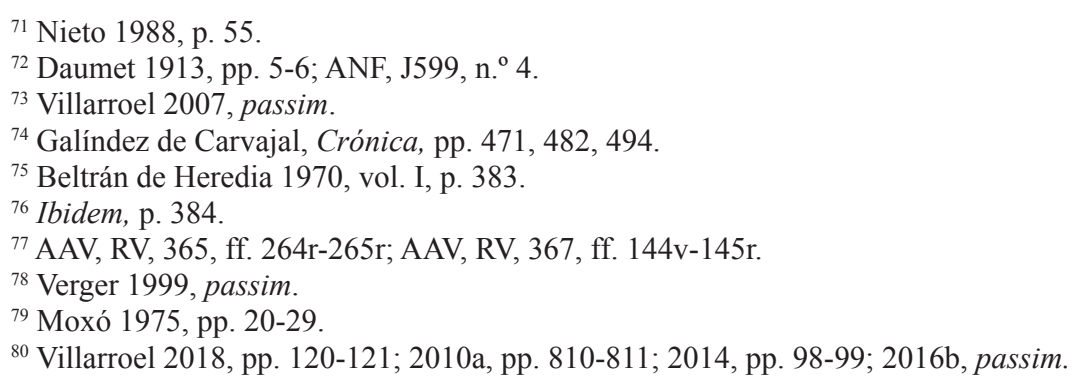


sos podemos afirmar que la formación fue fundamental en sus carreras ${ }^{81}$; sin embargo, el problema estriba en que las fuentes suelen ser parcas a la hora de dar información y habitualmente hay una amplia mayoría de personajes de los que no tenemos ninguna. $Y$ esto, efectivamente, podemos comprobarlo en el elenco que se presenta de los embajadores o procuradores de los reyes de Castilla en Curia.

Como se puede ver en el anexo 1 tan solo hay datos de 51 de entre los 153 casos recogidos. Además, y como ocurre en otros ámbitos, la información es muy desigual a lo largo de los siglos, no siendo habitual encontrar referencias a la formación hasta el siglo XV. Sin embargo, si analizamos los datos, también podemos extraer alguna conclusión interesante. Tomaremos en primer lugar el conjunto de los enviados a Curia.

Para empezar, del siglo XIII tenemos documentada la formación solo de diez de los procuradores o embajadores localizados. En estos casos suelen ser mencionados como magistrum o magister. En aquellos momentos tal título se ha considerado equivalente al posterior licenciatus y que eran maestros en leyes ${ }^{82}$. Pero, además, ocho de las menciones pertenecen a tres personas (Domingo Suárez, Randulfo de Podio Bonizi y Fernando Rodríguez). De esta forma, solo tenemos datos de 5 de los enviados. Obviamente, que no se indiquen estudios no quiere decir que no los tuviesen, pero aun así son menos de la cuarta parte del total de las 45 misiones que conocemos.

Para el siglo XIV se conservan datos de un total de 8 enviados. Esto es un buen indicativo del cambio de las fuentes con el paso del tiempo, pues el número de misiones documentadas en este siglo es muy inferior a las del siglo anterior: 33 en total. Eso nos muestra cómo vamos teniendo más información: las fuentes consideraban cada vez más relevante la formación de los diversos personajes y por eso la mencionaban. De hecho, también es llamativo que solo tenemos datos de un personaje anterior a 1350: Alvar García de Illas, que era alcalde del rey y las fuentes hablan de él como "jurista"83. El resto de los personajes de los que se nos facilitan sus estudios son posteriores. Es significativo, también, el hecho de que tenemos datos de siete personas distintas. Con ello, vemos que aumenta nuestro conocimiento sobre los saberes de los enviados regios y parece plausible que eso sea un reflejo de su incremento.

El siglo XV, como ya se ha comprobado en otros estudios, es un momento de incremento de la información que nos aportan las fuentes. En total hay datos de 33 embajadores, de un total de 72 . Como vemos, casi se alcanza el $50 \%$ del total. Lo que es, sin duda, una cifra mucho más relevante. Además,

${ }^{81}$ Ibidem, pp. 162-165.

${ }^{82}$ Domínguez 2007, p. 76.

${ }^{83}$ Serrano 1915, p. 5; AAV, RS, 1-1, f. 108; Torremocha 1994, pp. 62, 262; Carriazo 2021. 
en el siglo XV los datos son más variados, siendo una tónica que se inició ya a finales del XIV. No solo se nos decía que tenían una formación y un título, sino que se indicaba también la materia y especialidad (gráfico 2):

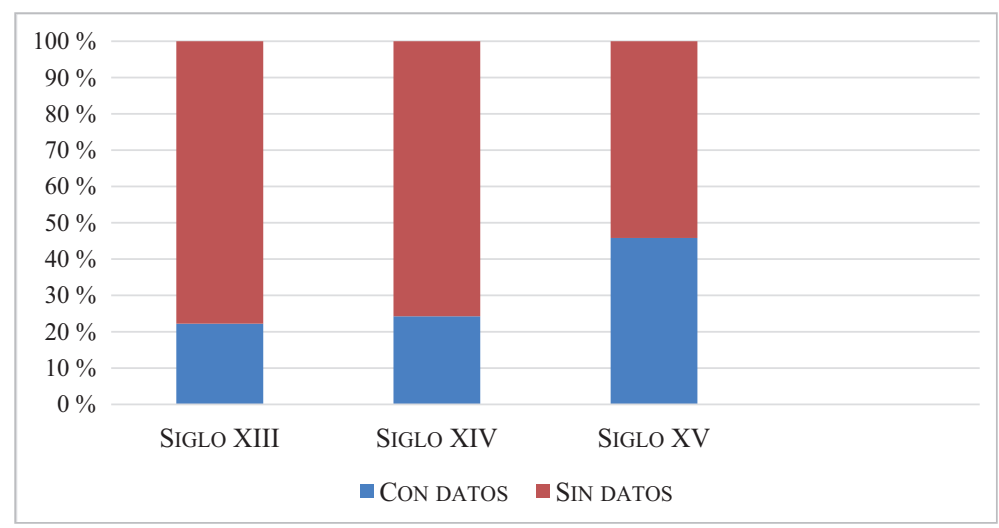

Gráfico 2. Procuradores y embajadores con datos de estudios

Con ello, además, podemos apreciar cuál era la formación que se repetía en más ocasiones. Así, contando todo el periodo analizado, el grado que aparece más veces es el de doctor, 20 (4 en el XIV y 16 en el XV), seguido de bachiller con 9 ( 1 y 8 respectivamente) y licenciado (solo 4), además del título de magister del XIII ya indicado y de dos embajadores de los que solo sabemos que estudiaron en una universidad, sin que se les asigne un título o nivel (gráfico 3).

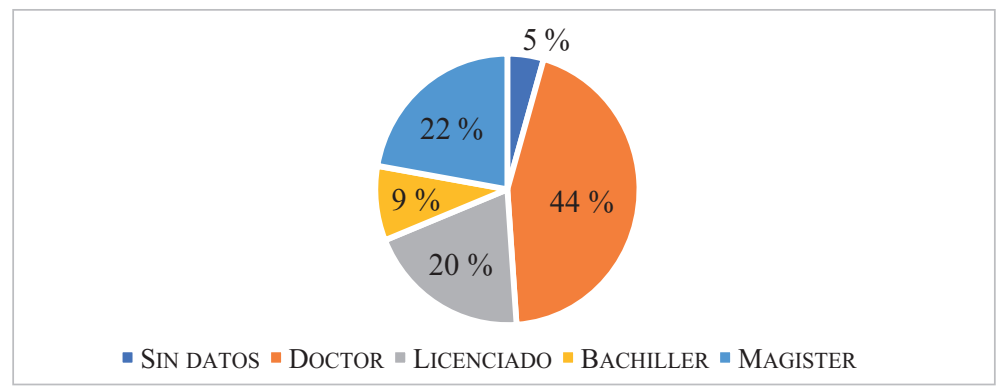

Gráfico 3. Grados alcanzados

Por último, en cuanto a las materias de estudio, priman aquellos de los que conocemos que estudiaron, pero no sabemos qué, siendo un total de 20. De muchos de ellos sabemos, incluso, que eran doctores, pero no se menciona su especialidad. Esto pone de manifiesto lo relevante que era el título de doctor (que se ponía por encima, incluso, de la especialidad). Después les si- 
guen los formados en derecho canónico (14), en derecho civil (13), hay 3 casos de ambos derechos y 6 de Teología. Dado que la mayor parte de los que sí conocemos datos habían estudiado derecho, ¿podría aventurarse que la mayor parte de los doctores lo fuesen en derecho? El hecho de que, en ocasiones, encontremos embajadores que tenían otros títulos, como doctor en Medicina ${ }^{84}$, hace que no aportemos tal hipótesis y no los consideremos como tales. Sería plausible, pero no dejaría de ser una hipótesis basada en un posible error (gráfico 4).

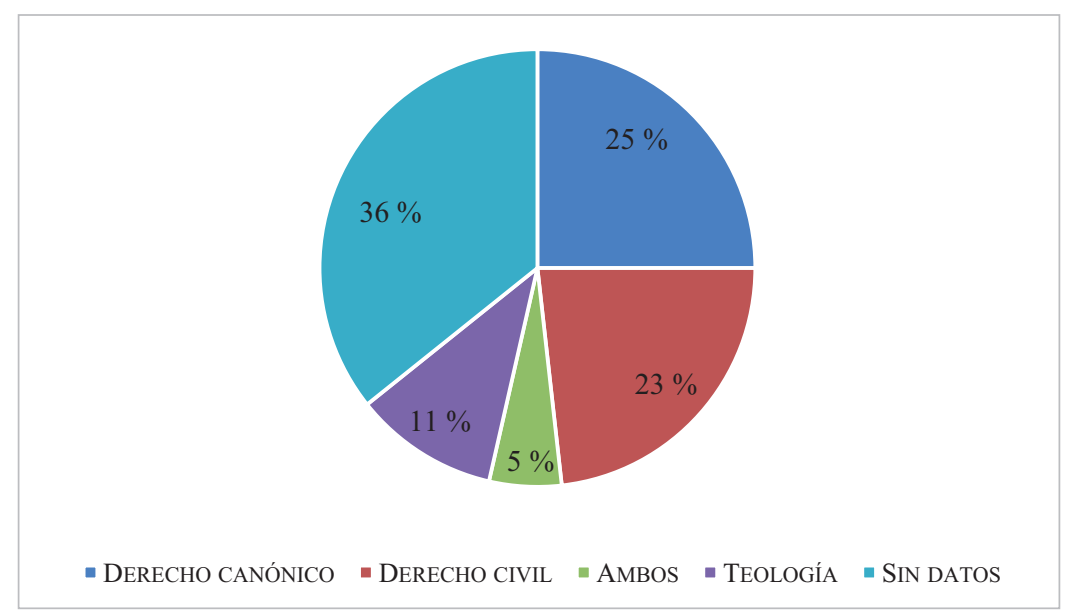

Gráfico 4. Especialidades

Con ello vemos que se está repitiendo una estructura de datos muy semejante a lo que se ha visto en otras ocasiones: un predominio de los doctores con formación jurídica (independientemente de la especialidad).

¿Y si nos atenemos solo a los prelados? ¿Hay cambios? Veremos que no muchos. Para empezar, solo tenemos datos de 10 prelados de los que las fuentes mencionan estudios universitarios. De un total de 33. Es decir, menos de una tercera parte del total y bastante en línea con lo que hemos visto que es la tónica general. De entre ellos, tenemos la información de un magistrum, formado en leyes en el XIII, junto a tres doctores, dos licenciados, un maestro en Teología y dos de los que solo sabemos que estudiaron en la universidad. En cuanto a las especialidades, hay dos en decretos, dos en leyes y uno en ambos derechos. Como vemos, el predominio del derecho es absoluto y la balanza entre los dos tipos se mantiene equilibrada. La única diferencia palpable

\footnotetext{
${ }^{84}$ Véase, por ejemplo, Fernando Díaz de Toledo, arcediano de Niebla, enviado por Alfonso V en varias ocasiones a Castilla: Villarroel 2011, pp. 599-601; Cingolani, Villarroel 2021.
} 
es la ausencia de bachilleres. Los prelados enviados a Curia o eran licenciados o doctores y primaba en ellos el conocimiento jurídico.

\section{A MODO DE CONCLUSIÓN}

Una vez revisada la lista de enviados ante el papa, y especialmente la de prelados, ¿qué podemos concluir? En primer lugar, parece claro que la historia de la diplomacia castellana ante el papado se enmarca en lo visto de manera general en el ámbito europeo del periodo. Son diversas las características que así nos lo muestran: la paulatina reducción de prelados en la diplomacia, la existencia de una gran mayoría de enviados que nunca repitieron misión, el incremento paulatino de su formación, el valor del derecho en los estudios de los embajadores...

También ha quedado de manifiesto cómo se fue incrementando, según avanzaba el tiempo, la presencia de eclesiásticos de menor rango en la representación regia ante la Curia. La reducción paulatina de forma cuantitativa de prelados fue palpable desde el siglo XIV, lo que contrasta sobre todo con el reinado de Alfonso X. Un momento especial, sin duda, por la importancia política y simbólica que pudieron tener los prelados en unas negociaciones cargadas de simbolismo. Pero fue un momento de cambio radical en este sentido. Hay, evidentemente, que analizar más pormenorizadamente los periodos anteriores (al menos desde un punto de vista de la historia de la diplomacia), pero es palpable cómo el servicio masivo de prelados en la representación regia en la Curia tuvo su canto de cisne con el rey sabio.

Obviamente lo cuantitativo no obsta a lo cualitativo. Siguió habiendo prelados en la representación, y alguno de ellos llevó a cabo misiones de notable importancia (como pudo ser el caso de Álvaro Núñez de Isorna y su embajada de 1421$)^{85}$. Sin embargo, la realidad en el día a día era otra, y las dignidades y oficiales habían tomado el relevo de forma evidente ya en esos años.

En el marco de los trabajos de este monográfico, ¿podemos pensar que el papel de los prelados como embajadores del rey castellano en Curia pudo suponer una fuente de influencia y contactos culturales? Ciertamente, aunque el número pueda parecer reducido, pensamos que sí pudo ser una fuente de influencia. Hay que tener en cuenta que sus estancias podían suponer una forma de adquirir conocimientos de tipo cultural y artístico. No solo ellos, sino también aquellos que componían sus séquitos que luego, en muchas ocasiones, alcanzaron

\footnotetext{
${ }^{85}$ Villarroel 2017.
} 
el episcopado también. Un buen ejemplo es Alfonso Carrillo ${ }^{86}$, que formando parte del séquito de su tío el cardenal y durante su formación en Bolonia adquirió múltiples influencias. Y a eso hay que añadir el elevado número de representantes localizados (que también las recibirían). Aunque pocos han sido analizados hasta hoy desde ese punto de vista, es algo que puede y debe hacerse. Sin duda es un trabajo pormenorizado, tanto en lo que toca a sus figuras políticas como a su papel artístico-cultural, que supera con mucho el marco de este trabajo.

A la vista de los nombres, resulta evidente que hubo algunos embajadores que tuvieron una notable influencia en el ámbito del humanismo, o al menos en su reflejo en Castilla. De esta forma, entre los que estuvieron en Curia nos encontramos con personajes de reconocido prestigio, y que han sido analizados frecuentemente a la hora de estudiar las influencias del humanismo en la península ibérica. Este podría ser el caso de Rodrigo Sánchez de Arévalo ${ }^{87}$, a quien sí hemos visto ante el papa ${ }^{88}$. Sin embargo, la mayor parte no han sido analizados aún desde ese punto de vista: prelados que repitieron misiones, como Martín Fernández, García Pérez o Alfonso de Ejea serían buenos ejemplos (aunque sí hayan sido objeto más o menos frecuente de análisis políticos) ${ }^{89}$.

Lo mismo debería hacerse con otros de los enviados que llegaron a la Curia no siendo prelados, pero algunos de los cuáles sí llegaron a serlo posteriormente. Especialmente aquellos que tuvieron más actividad diplomática: Alfonso de Argüello, Alfonso de Ejea, Álvaro Núñez de Isorna ${ }^{90}$, Fortún Velázquez de Cuéllar ${ }^{91}$, etc.

Pero, además, hay que tener en cuenta otra variable. Es evidente que la sede pontificia fue objeto de atracción para otros eclesiásticos que no fueron embajadores (aunque en su estancia no dudasen en actuar como representantes o defensores de los intereses del rey castellano). El mejor ejemplo es, sin duda, Gil de Albornoz. Este arzobispo de Toledo y luego cardenal no fue embajador en Curia (al menos hasta que se asentó en ella). Aunque se le ha presentado como tal en 1343, en aquella ocasión él era embajador ante el rey de Francia ${ }^{92}$. Sin embargo, sí estuvo en la sede pontificia, tanto al ir como al volver de su misión en París, así como en alguna visita ad limina ${ }^{93}$. Otro ejemplo sería Alfonso Carrillo de Acuña, prelado que, pese a sus estancias en Italia

${ }^{86}$ Véase, por ejemplo, Gil 2015; Moreno 1985.

${ }^{87}$ Son abundantísimos los trabajos; mencionaré solo algunos de los más recientes y centrados en la influencia cultural: Velázquez 1997; López, Ruiz 2014, 2015; Ruiz 2009.

${ }^{88}$ Véase el anexo 1.

${ }^{89}$ Por ejemplo, recientemente, Martín Fernández: Cavero 2018.

${ }^{90}$ Una obra desaparecida, como es su capilla funeraria, sí ha sido objeto de atención: Cendón 1995.

${ }^{91}$ En este último caso también ha habido análisis políticos de la familia: Diago 1991, 2009.

${ }^{92}$ Serrano 1915, pp. 17-18.

${ }^{93}$ Cañas 2019, p. 37. 
y en la corte papal, en el entorno de su tío el cardenal Carrillo, nunca tuvo el rango de embajador o representante regio ${ }^{94}$. De esta forma, ambos son un buen ejemplo de cómo las estancias en la Curia o en su entorno no pueden ser medidas por la presencia del prelado en cuestión como embajador. Y aunque de ambos se han realizado trabajos sobre su labor artística ${ }^{95}$, parece evidente que queda aún mucho por hacer.

En definitiva, es evidente el hecho de que hay mucho trabajo por delante. Con una lista de representantes del rey de Castilla ante el papa (aunque aún no podemos considerarla completa), entre prelados y no prelados, entre laicos y eclesiásticos, sin duda se nos ofrece una posibilidad para ampliar las búsquedas y encontrar unos contactos e influencias que hasta ahora han pasado desapercibidos. Todo ello, como se ha indicado, sin dejar de lado todas las otras influencias que podían llegar por todo el personal eclesiástico que, por unas razones u otras, se movía entre Castilla y la Curia.

\section{ANEXOS}

\subsection{Anexo 1. Embajadores y enviados a Curia por los reyes de}

\section{Castilla}

\begin{tabular}{|l|l|l|l|l|l|}
\hline Nombre & CARGO & $\begin{array}{c}\text { GRADO } \\
\text { DE } \\
\text { DIGNIDAD }\end{array}$ & AÑO & ESTUDIOS & \multicolumn{1}{|c|}{$\begin{array}{l}\text { FUENTE Y/O } \\
\text { BIBLIOGRAFÍA }\end{array}$} \\
\hline "Castella" & $\begin{array}{l}\text { Procurador } \\
\text { del rey }\end{array}$ & & 1251 & & $\begin{array}{l}\text { ACT, O. 1. F. 1. 33; } \\
\text { Linehan 1979, p. 104 }\end{array}$ \\
\hline $\begin{array}{l}\text { Martín } \\
\text { Fernández }\end{array}$ & $\begin{array}{l}\text { Obispo de } \\
\text { León }\end{array}$ & Obispo & 1254 & & $\begin{array}{l}\text { Domínguez 2003, doc. } \\
\text { 441; Cavero 2018, pp. } \\
115-116 .\end{array}$ \\
\hline $\begin{array}{l}\text { Fernando de } \\
\text { Covarrubias }\end{array}$ & & & 1257 & & $\begin{array}{l}\text { RAH, Salazar y } \\
\text { Castro, R1, ff. 298v- } \\
\text { 299r; Nieto 1988, } \\
\text { p. 54. }\end{array}$ \\
\hline $\begin{array}{l}\text { Domingo } \\
\text { Suárez }\end{array}$ & & & 1258 & & $\begin{array}{l}\text { Rodríguez R. de } \\
\text { Lama 1976, doc. 413; } \\
\text { Nieto 1988, p. 54. }\end{array}$ \\
\hline
\end{tabular}

${ }^{94}$ Díaz 2015; Mirecki 1991.

${ }^{95}$ Por ejemplo: Marías, Serra 2005. 


\begin{tabular}{|c|c|c|c|c|c|}
\hline Sancho & $\begin{array}{l}\text { Arzobispo } \\
\text { de Toledo, } \\
\text { infante y } \\
\text { hermano del } \\
\text { rey }\end{array}$ & Arzobispo & 1258 & $\begin{array}{l}\text { Estudió } \\
\text { en París }\end{array}$ & $\begin{array}{l}\text { Rodríguez R. de } \\
\text { Lama 1976, p. } 375 \text {; } \\
\text { Nieto } 1988 \text {, p. } 54 \text {. }\end{array}$ \\
\hline $\begin{array}{l}\text { Juan } \\
\text { Alfonso }\end{array}$ & $\begin{array}{l}\text { Maestre, } \\
\text { arcediano de } \\
\text { Santiago }\end{array}$ & Arcediano & 1259 & Maestre & $\begin{array}{l}\text { ARCV, Pergaminos, } \\
\text { carp. } 4,15 \text {. }\end{array}$ \\
\hline \multirow[t]{2}{*}{ Raimundo } & $\begin{array}{l}\text { Obispo de } \\
\text { Segovia }\end{array}$ & Obispo & 1259 & & $\begin{array}{l}\text { González } 2004, \\
\text { p. 134; Nieto } 1988, \\
\text { pp. 54-59; O'Callaghan } \\
\text { 1993, p. } 206 .\end{array}$ \\
\hline & $\begin{array}{l}\text { Abad de } \\
\text { Arvás }\end{array}$ & Abad & 1259 & & $\begin{array}{l}\text { González 2004, } \\
\text { p. } 134 .\end{array}$ \\
\hline Manuel & $\begin{array}{l}\text { Infante de } \\
\text { Castilla }\end{array}$ & & 1259 & & $\begin{array}{l}\text { González } 2004, \\
\text { p. } 134 \text {; Nieto } 1988 \\
\text { pp. } 54-59 .\end{array}$ \\
\hline $\begin{array}{l}\text { Martín } \\
\text { Fernández }\end{array}$ & $\begin{array}{l}\text { Obispo de } \\
\text { León }\end{array}$ & Obispo & 1261 & & $\begin{array}{l}\text { Domínguez } 2007 \text {, } \\
\text { pp. } 227-230 .\end{array}$ \\
\hline Agustín & $\begin{array}{l}\text { Obispo de } \\
\text { Osma }\end{array}$ & Obispo & 1262 & & $\begin{array}{l}\text { Nieto } 1988, \text { p. } 55 \\
\text { Ballesteros } 1918 \text {, } \\
\text { p. } 32 .\end{array}$ \\
\hline $\begin{array}{l}\text { Pedro } \\
\text { Lorenzo }\end{array}$ & $\begin{array}{l}\text { Obispo de } \\
\text { Cuenca }\end{array}$ & Obispo & 1262 & & $\begin{array}{l}\text { Nieto } 1988, \text { p. } 55 \\
\text { Ballesteros } 1918 \text {, } \\
\text { p. } 32 .\end{array}$ \\
\hline $\begin{array}{l}\text { Martín } \\
\text { Fernández }\end{array}$ & $\begin{array}{l}\text { Obispo de } \\
\text { León }\end{array}$ & Obispo & 1263 & & $\begin{array}{l}\text { Domínguez 2007, } \\
\text { pp. 118-119; Rodríguez } \\
\text { R. de Lama 1981, } \\
\text { pp. 99-100; O'Callaghan } \\
\text { 1993, p. 52. }\end{array}$ \\
\hline $\begin{array}{l}\text { García } \\
\text { ¿Pérez? }\end{array}$ & $\begin{array}{l}\text { Obispo de } \\
\text { Silves }\end{array}$ & Obispo & 1263 & & $\begin{array}{l}\text { Domínguez 2007, } \\
\text { pp. 118-119; Rodríguez } \\
\text { R. de Lama 1981, } \\
\text { pp. } 99-100 ; \text { Ayala } \\
\text { 2014-2015; Nieto } \\
\text { 1988,p. 55; O'Callaghan } \\
\text { 1993, p. 52. }\end{array}$ \\
\hline $\begin{array}{l}\text { Juan } \\
\text { Alfonso }\end{array}$ & $\begin{array}{l}\text { Arcediano } \\
\text { de Santiago, } \\
\text { capellán del } \\
\text { papa }\end{array}$ & Arcediano & 1263 & & $\begin{array}{l}\text { Domínguez } 2007 \text {, } \\
\text { pp. 118-119; Rodríguez } \\
\text { R. de Lama 1981, } \\
\text { pp. 99-100; Nieto } \\
\text { 1988, p. 55. }\end{array}$ \\
\hline
\end{tabular}




\begin{tabular}{|c|c|c|c|c|c|}
\hline $\begin{array}{l}\text { Domingo } \\
\text { Suárez }\end{array}$ & $\begin{array}{l}\text { Obispo de } \\
\text { Ávila }\end{array}$ & Obispo & 1263 & $\begin{array}{l}\text { Magis- } \\
\text { trum }\end{array}$ & $\begin{array}{l}\text { Domínguez 2007, } \\
\text { p. 104; Rodríguez R. } \\
\text { de Lama 1981, } \\
\text { pp. 142-147; Nieto 1988, } \\
\text { p. 55; O’Callaghan } \\
\text { 1993, p. 52. }\end{array}$ \\
\hline Pascual & Obispo de Jaén & Obispo & 1263 & & Nieto 1988 , p. 55. \\
\hline $\begin{array}{l}\text { Randulfo } \\
\text { de Podio } \\
\text { Bonizi }\end{array}$ & & & $\begin{array}{l}1263- \\
1264\end{array}$ & $\begin{array}{l}\text { Magis- } \\
\text { trum }\end{array}$ & $\begin{array}{l}\text { Domínguez 2007, } \\
\text { pp. 118-119; } \\
\text { Rodríguez R. de } \\
\text { Lama 1981, } \\
\text { pp. 99-100; Nieto } \\
\text { 1988, p. 55; } \\
\text { Hernández, Linehan } \\
\text { 2004, p. 101. }\end{array}$ \\
\hline $\begin{array}{l}\text { Juan de } \\
\text { Tudiño }\end{array}$ & & & 1264 & & $\begin{array}{l}\text { Domínguez } 2007 \text {, } \\
\text { p. } 228 ; \text { Rodríguez R. } \\
\text { de Lama 1981, } \\
\text { p. } 428 .\end{array}$ \\
\hline $\begin{array}{l}\text { García } \\
\text { ¿Pérez? }\end{array}$ & $\begin{array}{l}\text { Obispo de } \\
\text { Silves }\end{array}$ & Obispo & 1267 & & $\begin{array}{l}\text { González 2004, } \\
\text { p. 207; Domínguez } \\
\text { 1996, p. } 166 .\end{array}$ \\
\hline $\begin{array}{l}\text { Juan } \\
\text { Alfonso }\end{array}$ & $\begin{array}{l}\text { Arcediano de } \\
\text { Santiago }\end{array}$ & Arcediano & 1267 & & $\begin{array}{l}\text { González, 2004, } \\
\text { p. 206; Domínguez } \\
\text { Sánchez, 1996, } \\
\text { pp. 63-64, 125-126. }\end{array}$ \\
\hline \multirow[t]{2}{*}{ Martín } & Obispo & Obispo & 1267 & & $\begin{array}{l}\text { González 2004, } \\
\text { p. 206; Domínguez } \\
\text { 1996, pp. 63-64, } \\
\text { 125-126. }\end{array}$ \\
\hline & $\begin{array}{l}\text { Arcediano de } \\
\text { Salamanca }\end{array}$ & Arcediano & 1267 & & $\begin{array}{l}\text { González 2004, } \\
\text { p. 207; Domínguez } \\
\text { 1996, p. } 166 .\end{array}$ \\
\hline $\begin{array}{l}\text { Randulfo } \\
\text { de Podio } \\
\text { Bonizi }\end{array}$ & & & 1267 & & $\begin{array}{l}\text { Domínguez } 2007, \\
\text { p. } 228 ; 1996, \\
\text { pp. } 240-241 .\end{array}$ \\
\hline $\begin{array}{l}\text { Juan } \\
\text { Alfonso }\end{array}$ & $\begin{array}{l}\text { Arcediano de } \\
\text { Santiago }\end{array}$ & Arcediano & 1268 & & $\begin{array}{l}\text { González 2004, } \\
\text { p. 207; Domínguez } \\
\text { 1996, p. 183; 2007, } \\
\text { p. } 229 .\end{array}$ \\
\hline Pedro & $\begin{array}{l}\text { Deán de } \\
\text { Salamanca }\end{array}$ & Deán & 1268 & & $\begin{array}{l}\text { González 2004, } \\
\text { p. } 207 \text {; Domínguez } \\
\text { 1996, p. 183; 2007, } \\
\text { p. } 229 \text {. }\end{array}$ \\
\hline
\end{tabular}




\begin{tabular}{|c|c|c|c|c|c|}
\hline Juan & Deán de León & Deán & 1268 & & $\begin{array}{l}\text { González 2004, } \\
\text { p. 207; Domínguez } \\
\text { 1996, p. 183; 2007, } \\
\text { p. } 229 .\end{array}$ \\
\hline $\begin{array}{l}\text { Randulfo } \\
\text { de Podio } \\
\text { Bonizi }\end{array}$ & & & 1268 & & $\begin{array}{l}\text { Domínguez 2007, } \\
\text { p. } 228 ; 1996, \\
\text { pp. } 309-311 .\end{array}$ \\
\hline Aymar & $\begin{array}{l}\text { Obispo de } \\
\text { Ávila }\end{array}$ & Obispo & 1271 & & Nieto 1988 , p. 55. \\
\hline $\begin{array}{l}\text { Fernando } \\
\text { Martínez }\end{array}$ & $\begin{array}{l}\text { Obispo electo } \\
\text { de Oviedo }\end{array}$ & Obispo & 1271 & & Nieto 1988, p. 55. \\
\hline \multirow[t]{2}{*}{$\begin{array}{l}\text { Fernando } \\
\text { Velázquez }\end{array}$} & $\begin{array}{l}\text { Obispo de } \\
\text { Segovia }\end{array}$ & Obispo & 1271 & & Nieto 1988, p. 55. \\
\hline & $\begin{array}{l}\text { Notario real, } \\
\text { arcediano de } \\
\text { Zamora }\end{array}$ & Arcediano & 1271 & & $\begin{array}{l}\text { Domínguez } 2007 \text {, } \\
\text { pp. } 227-230 ; \\
\text { Nieto } 1988, \\
\text { p. } 55 .\end{array}$ \\
\hline Aldemaro & Dominico & Arcediano & 1272 & & $\begin{array}{l}\text { González 2004, } \\
\text { p. 234; Böhmer et al. } \\
\text { 1881-1901, vol. II, } \\
\text { p. 1035; Domínguez } \\
\text { 2007, p. 229; 1997, } \\
\text { pp. 139-144. }\end{array}$ \\
\hline $\begin{array}{l}\text { Fernando } \\
\text { Rodríguez }\end{array}$ & $\begin{array}{l}\text { Notario real, } \\
\text { Arcediano de } \\
\text { Zamora }\end{array}$ & Arcediano & 1272 & Magister & $\begin{array}{l}\text { González 2004, } \\
\text { p. 234; Böhmer et al. } \\
\text { 1881-1901, vol. II, } \\
\text { p. 1035; Domínguez } \\
\text { 2007, p. 229; 1997, } \\
\text { pp. 139-144. }\end{array}$ \\
\hline $\begin{array}{l}\text { Randulfo } \\
\text { de Podio } \\
\text { Bonizi }\end{array}$ & & & 1272 & & $\begin{array}{l}\text { Domínguez } 2007 \text {, } \\
\text { p. } 229 ; 1997, \\
\text { pp. } 139-144 .\end{array}$ \\
\hline $\begin{array}{l}\text { Juan de } \\
\text { Porta }\end{array}$ & $\begin{array}{l}\text { Miles et } \\
\text { nuncius }\end{array}$ & & 1273 & & $\begin{array}{l}\text { Dominguez } 2007 \text {, } \\
\text { p. } 107 ; 1997, \\
\text { pp. } 222-223 .\end{array}$ \\
\hline Aymar & $\begin{array}{l}\text { Obispo de } \\
\text { Ávila }\end{array}$ & Obispo & 1274 & & $\begin{array}{l}\text { Nieto } 1988, \text { p. } 56 \text {; } \\
\text { Potthast 1874-1875, } \\
\text { vol. II, p. 1679; } \\
\text { González 2004, } \\
\text { p. 278; Ballesteros } \\
\text { 1918, p. } 56 .\end{array}$ \\
\hline
\end{tabular}




\begin{tabular}{|c|c|c|c|c|c|}
\hline Aldemaro & & & 1274 & & $\begin{array}{l}\text { González 2004, } \\
\text { p. 234; Böhmer et al. } \\
\text { 1881-1901, vol. II, } \\
\text { p. 1035; Domínguez } \\
\text { 2007, p. 229; 1997, } \\
\text { pp. 139-144. }\end{array}$ \\
\hline $\begin{array}{l}\text { Melendo } \\
\text { Pérez }\end{array}$ & $\begin{array}{l}\text { Obispo de } \\
\text { Astorga }\end{array}$ & Obispo & 1274 & & $\begin{array}{l}\text { Domínguez 2007, } \\
\text { p. } 104 ; 1996 \text {, } \\
\text { pp. 238-240; Nieto } \\
\text { 1988, p. 56; Potthast } \\
\text { 1874-1875, p. 1679; } \\
\text { González 2004, } \\
\text { p. 278; Ballesteros } \\
\text { 1918, p. 56. }\end{array}$ \\
\hline $\begin{array}{l}\text { Juan Núñez } \\
\text { de Lara }\end{array}$ & & & 1274 & & $\begin{array}{l}\text { Domínguez 2007, } \\
\text { p. 230; 1996, } \\
\text { pp. 238-240; Ayala } \\
\text { 1987, pp. 10-11; } \\
\text { Nieto 1988, p. 56; } \\
\text { Potthast 1874-1875, } \\
\text { vol. II, p. 1679; } \\
\text { Ballesteros 1918, } \\
\text { p. } 56 .\end{array}$ \\
\hline $\begin{array}{l}\text { Fernando } \\
\text { Rodríguez }\end{array}$ & $\begin{array}{l}\text { Notario real, } \\
\text { Arcediano de } \\
\text { Zamora }\end{array}$ & Arcediano & 1274 & Magister & $\begin{array}{l}\text { Domínguez 2007, } \\
\text { p. 230; 1996, } \\
\text { pp. 238-240; Nieto } \\
\text { 1988, p. 56; Potthast } \\
\text { 1874-1875, vol. II, } \\
\text { p. 1679; González } \\
\text { 2004, p. 278; } \\
\text { Ballesteros 1918, } \\
\text { p. 56. }\end{array}$ \\
\hline $\begin{array}{l}\text { Frédulo } \\
\text { (según } \\
\text { Eubel) }\end{array}$ & $\begin{array}{l}\text { Obispo de } \\
\text { Oviedo }\end{array}$ & Obispo & 1278 & & Daumet 1913, p. 57. \\
\hline $\begin{array}{l}\text { Frédulo } \\
\text { (según } \\
\text { Eubel) }\end{array}$ & $\begin{array}{l}\text { Obispo de } \\
\text { Oviedo }\end{array}$ & Obispo & 1281 & & $\begin{array}{l}\text { Daumet } 1913 \text {, } \\
\text { pp. } 75-76 .\end{array}$ \\
\hline $\begin{array}{l}\text { Arias de } \\
\text { Medin }\end{array}$ & $\begin{array}{l}\text { Arcediano de } \\
\text { Lugo }\end{array}$ & Arcediano & 1294 & & $\begin{array}{l}\text { Nieto } 1988, \\
\text { pp. } 56-57 .\end{array}$ \\
\hline $\begin{array}{l}\text { Rodrigo } \\
\text { Vázquez }\end{array}$ & $\begin{array}{l}\text { Obispo de } \\
\text { Mondoñedo }\end{array}$ & Obispo & 1294 & & $\begin{array}{l}\text { Cal } 1999, \text { p. } 160, \\
\text { doc. } 70 ; \text { Nieto } 1988, \\
\text { p. } 57 \text {; BNE, ms. } \\
5928, \text { f. } 65 \mathrm{v} .\end{array}$ \\
\hline
\end{tabular}




\begin{tabular}{|c|c|c|c|c|c|}
\hline $\begin{array}{l}\text { Juan del } \\
\text { Campo }\end{array}$ & $\begin{array}{l}\text { Obispo de } \\
\text { León }\end{array}$ & Obispo & 1326 & & $\begin{array}{l}\text { Gran crónica de } \\
\text { Alfonso XI, } \\
\text { cap. CLIX, p. } 438 ; \\
\text { Crónica de Alfonso } \\
\text { XI, cap. LXVI, } \\
\text { p. } 213 \text {; Nieto 1988, } \\
\text { p. } 57 .\end{array}$ \\
\hline $\begin{array}{l}\text { Pedro } \\
\text { Martínez } \\
\text { Peñaranda }\end{array}$ & & & 1326 & & $\begin{array}{l}\text { Gran Crónica de } \\
\text { Alfonso XI, } \\
\text { cap. CLIX, p. 438; } \\
\text { Crónica de Alfonso } \\
\text { XI, cap. LXVI, p. } 213 .\end{array}$ \\
\hline $\begin{array}{l}\text { Ferrán } \\
\text { Sánchez de } \\
\text { Valladolid }\end{array}$ & & & 1326 & & $\begin{array}{l}\text { Gran Crónica de } \\
\text { Alfonso XI, } \\
\text { cap. CLIX, p. 438; } \\
\text { Crónica de Alfonso } \\
\text { XI, cap. LXVI, p. } 213 .\end{array}$ \\
\hline $\begin{array}{l}\text { Juan } \\
\text { Martínez de } \\
\text { Leyva }\end{array}$ & & & 1338 & & $\begin{array}{l}\text { Crónica de Alfonso } \\
\text { XI, p. 298; Ochoa } \\
\text { 1991, p. } 180 .\end{array}$ \\
\hline $\begin{array}{l}\text { Juan } \\
\text { Martínez de } \\
\text { Leyva }\end{array}$ & & & 1340 & & $\begin{array}{l}\text { Crónica de Alfonso } \\
\text { XI, cap. CCLIV, } \\
\text { p. 330; Ochoa 1991, } \\
\text { vol. I, pp. 181-182. }\end{array}$ \\
\hline $\begin{array}{l}\text { Alfonso } \\
\text { Ortiz } \\
\text { Calderón }\end{array}$ & $\begin{array}{l}\text { Prior de san } \\
\text { Juan }\end{array}$ & Prior & 1342 & & $\begin{array}{l}\text { Serrano } 1915, \text { p. } 13 \text {; } \\
\text { Crónica Alfonso XI, } \\
\text { cap. } 273 \text {, p. } 347 .\end{array}$ \\
\hline $\begin{array}{l}\text { Alfonso } \\
\text { Fernández } \\
\text { Coronel }\end{array}$ & Noble & & 1342 & & $\begin{array}{l}\text { Serrano } 1915, \text { p. } 4 \\
\text { Crónica Alfonso } X \\
\text { cap. } 280, \text { p. } 352 .\end{array}$ \\
\hline $\begin{array}{l}\text { Alvar } \\
\text { García de } \\
\text { Illas }\end{array}$ & $\begin{array}{l}\text { Alcalde de la } \\
\text { casa del rey }\end{array}$ & & 1342 & Jurista & $\begin{array}{l}\text { Serrano } 1915, \text { p. } 5 \text {; } \\
\text { AAV, RS, 1-1, f. 108; } \\
\text { Torremocha } 1994 \text {, } \\
\text { pp. } 62,262 \text {. }\end{array}$ \\
\hline $\begin{array}{l}\text { Rodrigo } \\
\text { Alonso de } \\
\text { Logroño }\end{array}$ & $\begin{array}{l}\text { Abad de San } \\
\text { Miguel de } \\
\text { Alfaro }\end{array}$ & Abad & 1344 & & Serrano 1915, p. 23. \\
\hline $\begin{array}{l}\text { García } \\
\text { Fernández } \\
\text { de Boneso }\end{array}$ & Caballero & & 1344 & & Serrano 1915 , p. 21 \\
\hline $\begin{array}{l}\text { Gonzalo de } \\
\text { Aguilar }\end{array}$ & $\begin{array}{l}\text { Obispo de } \\
\text { Sigüenza }\end{array}$ & Obispo & 1347 & & $\begin{array}{l}\text { Zunzunegui } 1960 \text {, } \\
\text { p. } 23 \text {; Ochoa 1991, } \\
\text { p. } 184 .\end{array}$ \\
\hline
\end{tabular}




\begin{tabular}{|c|c|c|c|c|c|}
\hline $\begin{array}{l}\text { Gonzalo } \\
\text { García de } \\
\text { Gallegos }\end{array}$ & & & 1347 & & Trenchs 1980, p. 15. \\
\hline $\begin{array}{l}\text { Rodrigo } \\
\text { Pérez de } \\
\text { Custos }\end{array}$ & $\begin{array}{l}\text { Doncel del } \\
\text { rey }\end{array}$ & & 1347 & & Trenchs 1980, p. 15. \\
\hline $\begin{array}{l}\text { Alvar } \\
\text { García de } \\
\text { Illas }\end{array}$ & $\begin{array}{l}\text { Alcalde de la } \\
\text { casa del rey }\end{array}$ & & 1349 & Jurista & Trenchs 1980, p. 15. \\
\hline $\begin{array}{l}\text { García } \\
\text { Gómez de } \\
\text { Soria }\end{array}$ & Capellán & & 1349 & & Trenchs 1980, p. 15. \\
\hline $\begin{array}{l}\text { Juan García } \\
\text { Palomeque }\end{array}$ & $\begin{array}{l}\text { Obispo de } \\
\text { Badajoz, } \\
\text { canciller } \\
\text { mayor }\end{array}$ & & 1371 & & $\begin{array}{l}\text { Daumet 1898, } \\
\text { pp. 168-169; AAV, } \\
\text { RV, 263, f. 61r; Díaz } \\
\text { 1988, p. } 68 .\end{array}$ \\
\hline $\begin{array}{l}\text { León de } \\
\text { Bocanegra }\end{array}$ & Almirante & & 1371 & & $\begin{array}{l}\text { Daumet } 1898 \text {, } \\
\text { pp. 168-169; AAV, } \\
\text { RV, 263, f. 61r. }\end{array}$ \\
\hline $\begin{array}{l}\text { Juan } \\
\text { Fernández }\end{array}$ & $\begin{array}{l}\text { Camarero del } \\
\text { infante Juan }\end{array}$ & & 1371 & & $\begin{array}{l}\text { Daumet } 1898 \text {, } \\
\text { pp. 168-169; AAV, } \\
\text { RV, 263, f. 61r }\end{array}$ \\
\hline $\begin{array}{l}\text { Pedro } \\
\text { Fernández }\end{array}$ & $\begin{array}{l}\text { Arcediano de } \\
\text { Treviño }\end{array}$ & Arcediano & 1376 & & Díaz 1988, p. 68. \\
\hline Ruy Bernal & $\begin{array}{l}\text { ¿Arcediano } \\
\text { Cuenca? }\end{array}$ & Arcediano & 1376 & & Díaz 1988, p. 68. \\
\hline $\begin{array}{l}\text { Juan } \\
\text { Ramírez de } \\
\text { Arellano }\end{array}$ & Noble & & 1376 & & Díaz 1988, p. 68. \\
\hline $\begin{array}{l}\text { Álvaro } \\
\text { Martínez }\end{array}$ & $\begin{array}{l}\text { Antes de ser } \\
\text { obispo de } \\
\text { Cuenca }\end{array}$ & $\begin{array}{l}\text { Prebenda- } \\
\text { do }\end{array}$ & 1378 & $\begin{array}{l}\text { Doctor en } \\
\text { decretos }\end{array}$ & Serra 2010 , p. 45. \\
\hline $\begin{array}{l}\text { Nicolás de } \\
\text { Viedma }\end{array}$ & $\begin{array}{l}\text { Obispo de } \\
\text { Cuenca }\end{array}$ & Obispo & 1378 & & Serra 2010, p. 47. \\
\hline $\begin{array}{l}\text { Fernando } \\
\text { de Illescas }\end{array}$ & $\begin{array}{l}\text { Confesor del } \\
\text { rey }\end{array}$ & Confesor & 1380 & & Díaz 1988, p. 73. \\
\hline Ruy Bernal & & & 1380 & & Díaz 1988, p. 73. \\
\hline $\begin{array}{l}\text { Tello } \\
\text { González }\end{array}$ & & & 1384 & & $\begin{array}{l}\text { Beolchini et al. 2011, } \\
\text { pp. 110-111, doc. } \\
165 .\end{array}$ \\
\hline
\end{tabular}




\begin{tabular}{|c|c|c|c|c|c|}
\hline $\begin{array}{l}\text { Pedro } \\
\text { García }\end{array}$ & $\begin{array}{l}\text { Capellán y } \\
\text { Embajador } \\
\text { del rey }\end{array}$ & $\begin{array}{l}\text { Porciona- } \\
\text { rio }\end{array}$ & 1389 & & $\begin{array}{l}\text { Beltrán de Heredia } \\
\text { 1966, vol. I, p. } 474\end{array}$ \\
\hline $\begin{array}{l}\text { Juan } \\
\text { Rodríguez }\end{array}$ & $\begin{array}{l}\text { Doctor en } \\
\text { leyes }\end{array}$ & & 1389 & $\begin{array}{l}\text { Doctor en } \\
\text { leyes }\end{array}$ & $\begin{array}{l}\text { Beltrán de Heredia } \\
\text { 1970, vol. I, } \\
\text { pp. } 472-473, \\
\text { doc. 188; AAV, RS, } \\
76 \text {, ff. 39-41. }\end{array}$ \\
\hline $\begin{array}{l}\text { Alfonso de } \\
\text { Ejea }\end{array}$ & $\begin{array}{l}\text { Obispo de } \\
\text { Zamora }\end{array}$ & Obispo & 1391 & & $\begin{array}{l}\text { Beltrán de Heredia } \\
\text { 1970, vol. I, } \\
\text { pp. } 482-483, \\
\text { doc. } 209 ; \text { AAV, RS, } \\
79 \text {, ff. } 81-82 .\end{array}$ \\
\hline $\begin{array}{l}\text { Gonzalo } \\
\text { Rodríguez }\end{array}$ & $\begin{array}{l}\text { Canónigo de } \\
\text { Burgos }\end{array}$ & Canónigo & 1392 & $\begin{array}{l}\text { Bachiller } \\
\text { en } \\
\text { decretos }\end{array}$ & $\begin{array}{l}\text { Suárez 1994, p. 81; } \\
\text { AAV, RV, 306, } \\
\text { ff. } 519 \mathrm{r}-520 \mathrm{r} \text {. }\end{array}$ \\
\hline $\begin{array}{l}\text { Domingo } \\
\text { Fernández } \\
\text { de } \\
\text { Cándamo }\end{array}$ & $\begin{array}{l}\text { Tesorero de } \\
\text { Oviedo }\end{array}$ & Tesorero & 1394 & $\begin{array}{l}\text { Doctor en } \\
\text { decretos }\end{array}$ & $\begin{array}{l}\text { Cuella 2011, p. 167; } \\
\text { AAV, RA, 281, } \\
\text { ff. } 441 \mathrm{v}-442 \mathrm{v} .\end{array}$ \\
\hline $\begin{array}{l}\text { Pedro } \\
\text { Martínez de } \\
\text { Frómista }\end{array}$ & $\begin{array}{l}\text { Arcipreste de } \\
\text { Población }\end{array}$ & Arcipreste & 1394 & & $\begin{array}{l}\text { Cuella 2011, p. 167; } \\
\text { AAV, RA, } 278, \\
\text { ff. } 402 \mathrm{v}-403 .\end{array}$ \\
\hline $\begin{array}{l}\text { Alfonso } \\
\text { Rodríguez } \\
\text { de } \\
\text { Salamanca }\end{array}$ & $\begin{array}{l}\text { Doctor, } \\
\text { catedrático de } \\
\text { Salamanca }\end{array}$ & & 1397 & Doctor & $\begin{array}{l}\text { Díaz 1988, p. } 77 ; \\
\text { Beltrán de Heredia } \\
\text { 1970, vol. I, p. } 154 .\end{array}$ \\
\hline $\begin{array}{l}\text { Fernando } \\
\text { de Illescas }\end{array}$ & $\begin{array}{l}\text { Maestro, } \\
\text { secretario de } \\
\text { Pedro Tenorio }\end{array}$ & Confesor & 1398 & $\begin{array}{l}\text { Maestro } \\
\text { en } \\
\text { Teología }\end{array}$ & $\begin{array}{l}\text { Díaz 1988, p. 78; } \\
\text { Beltrán de Heredia } \\
\text { 1970, vol. I, p. } 154 .\end{array}$ \\
\hline $\begin{array}{l}\text { Alfonso de } \\
\text { Argüello }\end{array}$ & & & 1401 & & Díaz 1988, p. 78. \\
\hline $\begin{array}{l}\text { Alfonso } \\
\text { Rodríguez } \\
\text { de } \\
\text { Salamanca }\end{array}$ & Doctor & & 1401 & Doctor & Díaz 1988, p. 78. \\
\hline $\begin{array}{l}\text { Pedro } \\
\text { Fernández } \\
\text { de Cámara }\end{array}$ & $\begin{array}{l}\text { Secretario real } \\
\text { y contador }\end{array}$ & & 1403 & Doctor & $\begin{array}{l}\text { Díaz 1988, p. 77; } \\
\text { Suárez 1960, } \\
\text { pp. 49, 243-347; } \\
\text { AGS, Estado-Castilla, } \\
\text { leg. 1-1, f. 48. }\end{array}$ \\
\hline $\begin{array}{l}\text { Pedro } \\
\text { Yáñez }\end{array}$ & $\begin{array}{l}\text { Secretario del } \\
\text { Consejo }\end{array}$ & & 1403 & Doctor & $\begin{array}{l}\text { Díaz 1988, p. 77; } \\
\text { Suárez 1960, p. } 49 .\end{array}$ \\
\hline
\end{tabular}




\begin{tabular}{|c|c|c|c|c|c|}
\hline $\begin{array}{l}\text { Juan } \\
\text { Alfonso de } \\
\text { Madrid }\end{array}$ & $\begin{array}{l}\text { Arcediano de } \\
\text { Alcaraz }\end{array}$ & Arcediano & 1404 & & Díaz 1988, p. 77. \\
\hline $\begin{array}{l}\text { Gonzalo } \\
\text { Moro }\end{array}$ & & & 1404 & & $\begin{array}{l}\text { Suárez 1960, } \\
\text { p. } 256 \text {; AGS, Estado- } \\
\text { Castilla, 1-1, f. } 54 \text {. }\end{array}$ \\
\hline $\begin{array}{l}\text { Alfonso de } \\
\text { Alcocer }\end{array}$ & $\begin{array}{l}\text { Confesor del } \\
\text { rey }\end{array}$ & Confesor & 1405 & & Díaz 1988, p. 78. \\
\hline $\begin{array}{l}\text { Alfonso de } \\
\text { Argüello }\end{array}$ & $\begin{array}{l}\text { Obispo de } \\
\text { León }\end{array}$ & Obispo & 1405 & $\begin{array}{l}\text { Maestro } \\
\text { en } \\
\text { Teología }\end{array}$ & $\begin{array}{l}\text { Suárez 1960, } \\
\text { p. } 257 \text {; AGS, Estado- } \\
\text { Castilla, 1-1, f. } 53 \text {. }\end{array}$ \\
\hline $\begin{array}{l}\text { Alfonso de } \\
\text { Ejea }\end{array}$ & $\begin{array}{l}\text { Arzobispo de } \\
\text { Sevilla }\end{array}$ & Arzobispo & 1405 & & Díaz 1988, p. 78. \\
\hline $\begin{array}{l}\text { Juan } \\
\text { Alfonso de } \\
\text { Madrid }\end{array}$ & $\begin{array}{l}\text { Arcediano de } \\
\text { Alcaraz }\end{array}$ & Arcediano & 1405 & & Díaz 1988, p. 77. \\
\hline $\begin{array}{l}\text { Fernán } \\
\text { Pérez de } \\
\text { Ayala }\end{array}$ & Noble & & 1405 & & Díaz 1988, p. 78. \\
\hline $\begin{array}{l}\text { Alfonso de } \\
\text { Alcocer }\end{array}$ & $\begin{array}{l}\text { Confesor del } \\
\text { rey }\end{array}$ & Confesor & 1406 & & Díaz 1988, p. 78. \\
\hline $\begin{array}{l}\text { Fernán } \\
\text { López de } \\
\text { Stúñiga }\end{array}$ & Noble & & 1406 & & Díaz 1988, p. 78. \\
\hline $\begin{array}{l}\text { Alfonso } \\
\text { Rodríguez }\end{array}$ & Jurista & & 1406 & Doctor & $\begin{array}{l}\text { Cuella 2009, p. 147; } \\
\text { AAV, RA, 328, } \\
\text { ff. 10-11r; Díaz 1988, } \\
\text { p. 78; Suárez 1960, } \\
\text { pp. 56-58, } 277 \text {. }\end{array}$ \\
\hline $\begin{array}{l}\text { Alfonso de } \\
\text { Argüello }\end{array}$ & $\begin{array}{l}\text { Obispo de } \\
\text { León }\end{array}$ & Obispo & 1407 & & $\begin{array}{l}\text { Cuella 2011, p. 206; } \\
\text { AAV, RA, } 369 \text {, } \\
\text { f. } 62 \text { r-v. }\end{array}$ \\
\hline $\begin{array}{l}\text { Diego } \\
\text { López }\end{array}$ & $\begin{array}{l}\text { Arcediano de } \\
\text { Deza }\end{array}$ & Arcediano & 1407 & & $\begin{array}{l}\text { Villarroel 2011, } \\
\text { p. } 133 .\end{array}$ \\
\hline $\begin{array}{l}\text { Fernando } \\
\text { García }\end{array}$ & $\begin{array}{l}\text { Bachiller y } \\
\text { capellán de la } \\
\text { reina }\end{array}$ & Prior & 1407 & Bachiller & $\begin{array}{l}\text { Díaz 1988, p. 81; } \\
\text { Suárez 1960, p. } 278 .\end{array}$ \\
\hline $\begin{array}{l}\text { Juan } \\
\text { Rodríguez } \\
\text { de Villalón }\end{array}$ & $\begin{array}{l}\text { Prior de } \\
\text { Husillos }\end{array}$ & Prior & 1407 & $\begin{array}{l}\text { Bachiller } \\
\text { en } \\
\text { decretos }\end{array}$ & $\begin{array}{l}\text { Díaz 1988, p. 81; } \\
\text { Suárez 1960, p. } 278 .\end{array}$ \\
\hline
\end{tabular}




\begin{tabular}{|c|c|c|c|c|c|}
\hline $\begin{array}{l}\text { Pedro } \\
\text { Fernández }\end{array}$ & $\begin{array}{l}\text { Arcediano del } \\
\text { Alcor }\end{array}$ & Arcediano & 1407 & & $\begin{array}{l}\text { Díaz 1988, p. 81; } \\
\text { Suárez 1960, p. } 281 \text {; } \\
\text { Nieto } 1993 \text { b, p. } 287 .\end{array}$ \\
\hline $\begin{array}{l}\text { Fernando } \\
\text { Martínez } \\
\text { Dávalos }\end{array}$ & $\begin{array}{l}\text { Deán de } \\
\text { Segovia }\end{array}$ & Deán & 1409 & & $\begin{array}{l}\text { Beltrán de Heredia } \\
1970 \text {, vol. I, p. } 258 .\end{array}$ \\
\hline $\begin{array}{l}\text { Juan de } \\
\text { Cervantes }\end{array}$ & $\begin{array}{l}\text { Arcediano de } \\
\text { Calatrava }\end{array}$ & Arcediano & 1417 & $\begin{array}{l}\text { Bachiller } \\
\text { en leyes, } \\
\text { maestro en } \\
\text { Teología }\end{array}$ & $\begin{array}{l}\text { Beltrán de Heredia } \\
\text { 1966, vol. II, } \\
\text { pp. 130-131. }\end{array}$ \\
\hline $\begin{array}{l}\text { Pedro } \\
\text { Fernández } \\
\text { de Cámara }\end{array}$ & $\begin{array}{l}\text { Secretario } \\
\text { real, capellán } \\
\text { apostólico }\end{array}$ & Arcediano & 1417 & Doctor & $\begin{array}{l}\text { Beltrán de Heredia } \\
\text { 1966, vol. II, } \\
\text { pp. } 216-217 .\end{array}$ \\
\hline $\begin{array}{l}\text { Juan de } \\
\text { Cervantes }\end{array}$ & $\begin{array}{l}\text { Arcediano de } \\
\text { Calatrava }\end{array}$ & Arcediano & 1419 & $\begin{array}{l}\text { Bachiller } \\
\text { en leyes, } \\
\text { maestro en } \\
\text { Teología }\end{array}$ & $\begin{array}{l}\text { Beltrán de Heredia } \\
\text { 1966, vol. II, } \\
\text { pp. 130-131. }\end{array}$ \\
\hline $\begin{array}{l}\text { Gutierre de } \\
\text { Toledo }\end{array}$ & $\begin{array}{l}\text { Arcediano de } \\
\text { Guadalajara }\end{array}$ & Arcediano & 1420 & & $\begin{array}{l}\text { Galíndez de Carvajal, } \\
\text { Crónica, p. } 388 .\end{array}$ \\
\hline $\begin{array}{l}\text { Álvaro } \\
\text { Núñez de } \\
\text { Isorna }\end{array}$ & $\begin{array}{l}\text { Obispo de } \\
\text { Cuenca }\end{array}$ & Obispo & 1421 & $\begin{array}{l}\text { Licencia- } \\
\text { do en } \\
\text { decretos }\end{array}$ & $\begin{array}{l}\text { Beltrán de Heredia } \\
\text { 1970, vol. I, p. } 403 .\end{array}$ \\
\hline $\begin{array}{l}\text { Juan } \\
\text { Alfonso de } \\
\text { Mella }\end{array}$ & $\begin{array}{l}\text { Cantor } \\
\text { de Coria, } \\
\text { canónigo } \\
\text { de Salamanca } \\
\text { y Zamora }\end{array}$ & Cantor & 1423 & $\begin{array}{l}\text { Doctor en } \\
\text { decretos }\end{array}$ & $\begin{array}{l}\text { Suárez 1960, } \\
\text { pp. 319-320; AAV, } \\
\text { RV, 354, } \\
\text { ff. } 167 \mathrm{v}-168 \mathrm{r} \text {. }\end{array}$ \\
\hline $\begin{array}{l}\text { Juan } \\
\text { Martínez } \\
\text { Contreras }\end{array}$ & $\begin{array}{l}\text { Arzobispo } \\
\text { de Toledo, } \\
\text { consejero real }\end{array}$ & Arzobispo & 1423 & $\begin{array}{l}\text { Licenciado } \\
\text { en decretos, } \\
\text { bachiller } \\
\text { en leyes }\end{array}$ & $\begin{array}{l}\text { Villarroel } 2016 \mathrm{c} ; \\
\text { ACT, A. 8. L. } 1.8 . \\
1 .{ }^{\circ} .\end{array}$ \\
\hline $\begin{array}{l}\text { Ruy } \\
\text { García de } \\
\text { Villaquirán }\end{array}$ & $\begin{array}{l}\text { Canónigo de } \\
\text { Toledo }\end{array}$ & Canónigo & 1423 & $\begin{array}{l}\text { Doctor en } \\
\text { leyes }\end{array}$ & $\begin{array}{l}\text { Villarroel } 2003 \mathrm{a} \text {, } \\
\text { pp. } 270-273 \text {; ACT, A. } \\
\text { 8. L. 1. 8. } 1 .^{\circ} \text { y } 2 .^{\mathrm{a}} \text {. }\end{array}$ \\
\hline $\begin{array}{l}\text { Sancho de } \\
\text { Rojas }\end{array}$ & $\begin{array}{l}\text { Oidor de la } \\
\text { Audiencia }\end{array}$ & Obispo & 1423 & $\begin{array}{l}\text { Estudios en } \\
\text { universi- } \\
\text { dad de } \\
\text { Cánones y } \\
\text { Filosofía }\end{array}$ & $\begin{array}{l}\text { Suárez 1960, p. 322; } \\
\text { AAV, RV, 359, } \\
\text { f. } 15 \text { r-v. }\end{array}$ \\
\hline $\begin{array}{l}\text { Rodrigo de } \\
\text { Perea }\end{array}$ & $\begin{array}{l}\text { Mayordomo } \\
\text { regio }\end{array}$ & & 1423 & & $\begin{array}{l}\text { Villarroel 2003a, } \\
\text { pp. } 270-273 ; \text { ACT, A. } \\
\text { 8. L. 1. 8. 1. } .^{\circ} \text { y } .^{\mathrm{a}}\end{array}$ \\
\hline
\end{tabular}




\begin{tabular}{|c|c|c|c|c|c|}
\hline $\begin{array}{l}\text { Juan } \\
\text { Álvarez de } \\
\text { Toledo }\end{array}$ & $\begin{array}{l}\text { Canónigo } \\
\text { de Palencia } \\
\text { y Toledo, } \\
\text { propuesto } \\
\text { arcediano } \\
\text { de Madrid, } \\
\text { hermano } \\
\text { del señor de } \\
\text { Oropesa }\end{array}$ & Canónigo & 1429 & $\begin{array}{l}\text { Bachiller } \\
\text { en } \\
\text { decretos }\end{array}$ & $\begin{array}{l}\text { Beltrán de Heredia } \\
\text { 1966, vol. II, p. } 332 .\end{array}$ \\
\hline $\begin{array}{l}\text { Rodrigo } \\
\text { Gutiérrez de } \\
\text { Barcenilla }\end{array}$ & $\begin{array}{l}\text { Secretario del } \\
\text { rey, arcediano } \\
\text { de Toro }\end{array}$ & Arcediano & 1432 & & $\begin{array}{l}\text { ASR, Camerale I, } \\
\text { 1712, f. 2v; Galíndez } \\
\text { de Carvajal, Crónica, } \\
\text { p. 504; Beltrán de } \\
\text { Heredia 1966, vol. II, } \\
\text { p. } 363 \text {. }\end{array}$ \\
\hline $\begin{array}{l}\text { Juan } \\
\text { Alfonso de } \\
\text { Mella }\end{array}$ & $\begin{array}{l}\text { Arcediano } \\
\text { de Madrid, } \\
\text { capellán } \\
\text { pontificio, } \\
\text { oidor del } \\
\text { Sacro Palacio }\end{array}$ & Arcediano & 1433 & $\begin{array}{l}\text { Licen- } \\
\text { ciado en } \\
\text { Decretos }\end{array}$ & $\begin{array}{l}\text { Beltrán de Heredia } \\
\text { 1966, vol. II, p. } 374 .\end{array}$ \\
\hline $\begin{array}{l}\text { Gil } \\
\text { Fernández } \\
\text { de Alfaro }\end{array}$ & Clérigo & & 1434 & & $\begin{array}{l}\text { García de Santa } \\
\text { María 1891, vol. II, } \\
\text { p. } 405 .\end{array}$ \\
\hline $\begin{array}{l}\text { Pedro de } \\
\text { Bocanegra }\end{array}$ & $\begin{array}{l}\text { Deán de } \\
\text { Cuenca }\end{array}$ & Deán & 1436 & $\begin{array}{l}\text { Licencia- } \\
\text { do en } \\
\text { Leyes }\end{array}$ & $\begin{array}{l}\text { Beltrán de Heredia } \\
\text { 1966, vol. II, p. } 417 .\end{array}$ \\
\hline $\begin{array}{l}\text { Alfonso } \\
\text { González } \\
\text { de Herrera }\end{array}$ & $\begin{array}{l}\text { Abad de Santa } \\
\text { Colomba } \\
\text { (Sigüenza) }\end{array}$ & Abad & 1439 & $\begin{array}{l}\text { Bachiller } \\
\text { en } \\
\text { Decretos }\end{array}$ & $\begin{array}{l}\text { AGS, Estado- } \\
\text { Francia, K1711, } \\
\text { ff. } 417 \mathrm{r}-421 \mathrm{r} .\end{array}$ \\
\hline $\begin{array}{l}\text { Rodrigo } \\
\text { Sánchez de } \\
\text { Arévalo }\end{array}$ & $\begin{array}{l}\text { Secretario } \\
\text { real, } \\
\text { arcediano de } \\
\text { Treviño }\end{array}$ & Arcediano & 1441 & $\begin{array}{l}\text { Bachiller } \\
\text { en ambos } \\
\text { derechos }\end{array}$ & $\begin{array}{l}\text { AAV, RV, 365, } \\
\text { ff. } 264 \mathrm{r}-265 \mathrm{r} ; \mathrm{AAV} \text {, } \\
\text { RV, } 367 \text {, } \\
\text { ff. } 144 \mathrm{v}-145 \mathrm{r} .\end{array}$ \\
\hline $\begin{array}{l}\text { Alfonso } \\
\text { González } \\
\text { de Herrera }\end{array}$ & $\begin{array}{l}\text { Abad de Santa } \\
\text { Colomba } \\
\text { (Sigüenza) }\end{array}$ & Abad & 1442 & $\begin{array}{l}\text { Bachiller } \\
\text { en } \\
\text { Decretos }\end{array}$ & $\begin{array}{l}\text { Nieto } 2004, \\
\text { pp. } 1067-1069 ; \\
\text { ACDAlba, leg. 222- } \\
5, \mathrm{~s} / \mathrm{n} .\end{array}$ \\
\hline $\begin{array}{l}\text { Fortún } \\
\text { Velázquez } \\
\text { de Cuéllar }\end{array}$ & $\begin{array}{l}\text { Arcediano de } \\
\text { Cuéllar }\end{array}$ & Arcediano & 1443 & $\begin{array}{l}\text { Doctor } \\
\text { en ambos } \\
\text { derechos }\end{array}$ & $\begin{array}{l}\text { AAV, RV, } 367 \text {, } \\
\text { f. } 165 \mathrm{r} \text {. }\end{array}$ \\
\hline Juan García & $\begin{array}{l}\text { Canónigo } \\
\text { de Palencia, } \\
\text { Capellán real }\end{array}$ & Canónigo & 1445 & & $\begin{array}{l}\text { AAV, RL, } 420 \text {, } \\
\text { ff. } 303 v-304 v .\end{array}$ \\
\hline
\end{tabular}




\begin{tabular}{|c|c|c|c|c|c|}
\hline $\begin{array}{l}\text { Francisco } \\
\text { de Toledo }\end{array}$ & $\begin{array}{l}\text { Deán de } \\
\text { Toledo }\end{array}$ & Deán & 1449 & & $\begin{array}{l}\text { Benito } 1960 \text {, } \\
\text { pp. } 52-53 .\end{array}$ \\
\hline $\begin{array}{l}\text { Juan de } \\
\text { Torquemada }\end{array}$ & $\begin{array}{l}\text { Cardenal de } \\
\text { San Sixto } \\
\text { (hacía un } \\
\text { año había } \\
\text { renunciado al } \\
\text { obispado de } \\
\text { Orense) }\end{array}$ & Cardenal & 1449 & $\begin{array}{l}\text { Doctor en } \\
\text { Teología } \\
\text { ¿y } \\
\text { Derecho? }\end{array}$ & $\begin{array}{l}\text { Benito } 1960 \text {, } \\
\text { pp. } 52-53 .\end{array}$ \\
\hline $\begin{array}{l}\text { Luis } \\
\text { González } \\
\text { de Atienza }\end{array}$ & $\begin{array}{l}\text { Secretario } \\
\text { real, maestres- } \\
\text { cuela de } \\
\text { Sigüenza }\end{array}$ & $\begin{array}{l}\text { Maestres- } \\
\text { cuela }\end{array}$ & 1453 & & $\begin{array}{l}\text { Zurita 2003, libro } \\
\text { XVI, cap. } 28 \text {, p. } 58 .\end{array}$ \\
\hline $\begin{array}{l}\text { Pedro } \\
\text { Fernández } \\
\text { de Solís }\end{array}$ & $\begin{array}{l}\text { Tesorero de } \\
\text { Salamanca }\end{array}$ & Tesorero & 1454 & & $\begin{array}{l}\text { González } 2019 \text {, } \\
\text { p. } 111 \text {; ACS, C. } 14 \text {, } \\
\text { leg. } 2, \text { n. }^{\circ} 17-1 .\end{array}$ \\
\hline $\begin{array}{l}\text { Íñigo López } \\
\text { de Mendoza }\end{array}$ & & & 1454 & & $\begin{array}{l}\text { González 2019, } \\
\text { p. 110; BNE, ms. } \\
10670 \text {, ff. 207-208r. } \\
\text { Cherubini } 1997 \text {, } \\
\text { pp. } 437-438 .\end{array}$ \\
\hline $\begin{array}{l}\text { Alonso de } \\
\text { Palenzuela }\end{array}$ & & & 1456 & & $\begin{array}{l}\text { Nieto } 1996, \text { p. } 193 \text {; } \\
\text { AAV, RV, } 457 \text {, } \\
\text { f. } 132 \text { v. }\end{array}$ \\
\hline $\begin{array}{l}\text { Diego de } \\
\text { Saldaña }\end{array}$ & $\begin{array}{l}\text { Clérigo } \\
\text { salmantino }\end{array}$ & & 1456 & & $\begin{array}{l}\text { Nieto } 1996, \text { p. } 196 \text {; } \\
\text { AAV, RV, 457, } \\
\text { f. } 132 \text { v. }\end{array}$ \\
\hline $\begin{array}{l}\text { Luis } \\
\text { González } \\
\text { de Atienza }\end{array}$ & $\begin{array}{l}\text { Secretario } \\
\text { real y deán de } \\
\text { Córdoba }\end{array}$ & Deán & 1456 & & $\begin{array}{l}\text { Zurita 2003, } \\
\text { vol. VII, libro XVI, } \\
\text { cap. } 38 \text {; González } \\
2019 \text {, p. } 110 \text {. }\end{array}$ \\
\hline $\begin{array}{l}\text { Rodrigo } \\
\text { Sánchez de } \\
\text { Arévalo }\end{array}$ & & & 1456 & $\begin{array}{l}\text { Doctor en } \\
\text { Leyes }\end{array}$ & $\begin{array}{l}\text { AAV, RV, 457, f. 107; } \\
\text { ACS, C. 14, leg. 1, } \\
\text { n. }{ }^{\circ} 10 \text {, f. 2v; González } \\
2019, \text { p. } 111 .\end{array}$ \\
\hline $\begin{array}{l}\text { Enrique de } \\
\text { Figueredo }\end{array}$ & & & 1456 & & $\begin{array}{l}\text { Zurita 2003, vol. VII, } \\
\text { libro XVI, cap. 38; } \\
\text { González 2019, p. } 110 .\end{array}$ \\
\hline $\begin{array}{l}\text { Juan de } \\
\text { Arce }\end{array}$ & $\begin{array}{l}\text { Abad de } \\
\text { Fronela }\end{array}$ & Abad & 1457 & & $\begin{array}{l}\text { Nieto } 1996, \text { p. } 194 ; \\
\text { AAV, RV, } 465 \text {, } \\
\text { ff. } 264 \mathrm{v} \text { y ss. }\end{array}$ \\
\hline $\begin{array}{l}\text { Alonso de } \\
\text { Palenzuela }\end{array}$ & & & 1458 & & Nieto 1996, p. 194. \\
\hline
\end{tabular}




\begin{tabular}{|c|c|c|c|c|c|}
\hline $\begin{array}{l}\text { Rodrigo } \\
\text { Sánchez de } \\
\text { Arévalo }\end{array}$ & & & 1458 & $\begin{array}{l}\text { Doctor en } \\
\text { Leyes }\end{array}$ & Nieto 1996, p. 194. \\
\hline $\begin{array}{l}\text { Fortún } \\
\text { Velázquez } \\
\text { de Cuéllar }\end{array}$ & $\begin{array}{l}\text { Obispo de } \\
\text { León }\end{array}$ & Obispo & 1460 & $\begin{array}{l}\text { Doctor } \\
\text { en ambos } \\
\text { derechos }\end{array}$ & $\begin{array}{l}\text { González 2019, } \\
\text { p. 110; Meserve, } \\
\text { Simonetta 2004, } \\
\text { vol. II, pp. 282-283. }\end{array}$ \\
\hline $\begin{array}{l}\text { Rodrigo } \\
\text { Sánchez de } \\
\text { Arévalo }\end{array}$ & $\begin{array}{l}\text { Obispo de } \\
\text { Oviedo }\end{array}$ & Obispo & 1460 & $\begin{array}{l}\text { Doctor en } \\
\text { Leyes }\end{array}$ & $\begin{array}{l}\text { Beltrán de Heredia } \\
\text { 1966, vol. III, p. 101; } \\
\text { Nieto 1996, p. } 195 .\end{array}$ \\
\hline $\begin{array}{l}\text { Íñigo López } \\
\text { de Mendoza }\end{array}$ & & & 1460 & & $\begin{array}{l}\text { González 2019, } \\
\text { p. 110; Meserve, } \\
\text { Simonetta 2004, } \\
\text { vol. II, pp. 282-283. }\end{array}$ \\
\hline $\begin{array}{l}\text { Íñigo López } \\
\text { de Mendoza }\end{array}$ & & & 1460 & & $\begin{array}{l}\text { Beltrán de Heredia } \\
\text { 1966, vol. III, p. 101; } \\
\text { Nieto 1996, p. } 195 .\end{array}$ \\
\hline $\begin{array}{l}\text { Alfonso de } \\
\text { Villarreal }\end{array}$ & $\begin{array}{l}\text { Fraile } \\
\text { franciscano }\end{array}$ & & 1463 & $\begin{array}{l}\text { Lector en } \\
\text { Teología }\end{array}$ & $\begin{array}{l}\text { López } 1943 \text {, p. } 546 \text {; } \\
\text { Nieto } 1996 \text {, p. } 195 .\end{array}$ \\
\hline $\begin{array}{l}\text { Juan de } \\
\text { Medina }\end{array}$ & $\begin{array}{l}\text { Arcediano de } \\
\text { Almazán }\end{array}$ & Arcediano & 1464 & & Nieto 1996, p. 195. \\
\hline $\begin{array}{l}\text { Rodrigo } \\
\text { Sánchez de } \\
\text { Arévalo }\end{array}$ & $\begin{array}{l}\text { Obispo de } \\
\text { Oviedo }\end{array}$ & Obispo & 1464 & $\begin{array}{l}\text { Doctor en } \\
\text { Leyes }\end{array}$ & $\begin{array}{l}\text { Álvarez 2010, } \\
\text { pp. 27-28. }\end{array}$ \\
\hline $\begin{array}{l}\text { Suero de } \\
\text { Solís }\end{array}$ & $\begin{array}{l}\text { Canónigo de } \\
\text { Burgos }\end{array}$ & Canónigo & 1464 & & $\begin{array}{l}\text { González 2019, } \\
\text { p. 111; 2018, p. 14; } \\
\text { Nieto 1996, p. 195; } \\
\text { ACB, Registro de } \\
\text { Actas 17, } \\
\text { ff. } 216 \mathrm{v}-219 \text { r. }\end{array}$ \\
\hline $\begin{array}{l}\text { Antonio } \\
\text { Jacobo de } \\
\text { Veneris }\end{array}$ & $\begin{array}{l}\text { Obispo de } \\
\text { León }\end{array}$ & Obispo & 1465 & $\begin{array}{l}\text { Lector en } \\
\text { Teología }\end{array}$ & $\begin{array}{l}\text { Álvarez 2010, } \\
\text { pp. 27-28; AHNob, } \\
\text { Frías, C. 12, doc. } 8 \text {; } \\
\text { González 2019, } \\
\text { p. } 111 .\end{array}$ \\
\hline $\begin{array}{l}\text { Rodrigo de } \\
\text { Vergara }\end{array}$ & $\begin{array}{l}\text { Arcediano de } \\
\text { Vizcaya }\end{array}$ & Arcediano & 1465 & Doctor & $\begin{array}{l}\text { Nieto 1996, p. 196; } \\
\text { González 2018, } \\
\text { p. } 14 .\end{array}$ \\
\hline Montoya & & & 1465 & & $\begin{array}{l}\text { González 2019, } \\
\text { p. } 110 \text {; AGS, } \\
\text { Secretaría Estado, } \\
\text { leg. I-1-2, f. } 128 .\end{array}$ \\
\hline
\end{tabular}




\begin{tabular}{|c|c|c|c|c|c|}
\hline $\begin{array}{l}\text { Diego de } \\
\text { Saldaña }\end{array}$ & & & 1470 & & $\begin{array}{l}\text { Palencia, Gesta } \\
\text { hispaniensia, } \\
\text { vol. II, p. 429; } \\
\text { González 2019, } \\
\text { p. } 110 .\end{array}$ \\
\hline $\begin{array}{l}\text { Francisco } \\
\text { de Toledo }\end{array}$ & $\begin{array}{l}\text { Deán de } \\
\text { Toledo }\end{array}$ & Deán & 1470 & $\begin{array}{l}\text { Doctor en } \\
\text { Teología }\end{array}$ & $\begin{array}{l}\text { Fernández 1963, } \\
\text { vol. I, pp. 52-53; } \\
\text { Cherubini 1997, } \\
\text { vol. I, pp. 1369-1370; } \\
\text { González 2019, p. } 111 .\end{array}$ \\
\hline $\begin{array}{l}\text { Fernando } \\
\text { de Arce }\end{array}$ & Secretario real & & 1470 & & $\begin{array}{l}\text { González 2019, } \\
\text { p. 110; AGS, } \\
\text { Patronato Real, } \\
\text { leg. 42, doc. } 37 .\end{array}$ \\
\hline $\begin{array}{l}\text { Juan de } \\
\text { Segovia }\end{array}$ & & & 1470 & & $\begin{array}{l}\text { Fernández 1963, } \\
\text { vol. I, pp. 52-53. }\end{array}$ \\
\hline $\begin{array}{l}\text { Diego de } \\
\text { Muros }\end{array}$ & $\begin{array}{l}\text { Abad de San } \\
\text { Clodio }\end{array}$ & Abad & 1471 & $\begin{array}{l}\text { Doctor en } \\
\text { Leyes }\end{array}$ & $\begin{array}{l}\text { Vázquez 1931, vol. I, } \\
\text { p. } 365 .\end{array}$ \\
\hline $\begin{array}{l}\text { Diego de } \\
\text { Saldaña }\end{array}$ & & & 1474 & Doctor & $\begin{array}{l}\text { Franco } 1997, \\
\text { pp. } 515-519 .\end{array}$ \\
\hline $\begin{array}{l}\text { Juan de } \\
\text { Arévalo }\end{array}$ & Secretario real & & 1474 & & $\begin{array}{l}\text { González 2019, } \\
\text { p. 112; AHNob, } \\
\text { Frías, C. } 113 \text {, doc. } 3 \text {. }\end{array}$ \\
\hline $\begin{array}{l}\text { Francisco } \\
\text { de } \\
\text { Santillana }\end{array}$ & $\begin{array}{l}\text { Chantre } \\
\text { de Sevilla, } \\
\text { canónigo de } \\
\text { Toledo }\end{array}$ & Chantre & $147 ?$ & & $\begin{array}{l}\text { González 2019, } \\
\text { p. 114; ACT, V.2. } \\
\text { D.1.14. }\end{array}$ \\
\hline
\end{tabular}

9.2. Anexo 2. Repetición de misiones por los prelados

\begin{tabular}{|c|c|c|c|}
\hline \multirow[b]{2}{*}{ PRELADO } & \multicolumn{2}{|c|}{ MISIÓN A CURIA } & \multirow{2}{*}{$\begin{array}{c}\text { OTRAS } \\
\text { MISIONES }\end{array}$} \\
\hline & $\begin{array}{c}\text { COMO } \\
\text { PRELADO }\end{array}$ & $\begin{array}{c}\text { OTRAS } \\
\text { FIGURAS }\end{array}$ & \\
\hline Agustín & 1 & & \\
\hline Alfonso de Argüello & 2 & 1 & \\
\hline Alfonso de Ejea & 2 & & 1 \\
\hline Álvaro Martínez & 1 & & 2 \\
\hline Álvaro Núñez de Isorna & 1 & & 1 \\
\hline
\end{tabular}




\begin{tabular}{|l|c|c|c|}
\hline Antonio Jacobo de Veneris & 1 & & \\
\hline Aymar & ¿2? & & 1 \\
\hline Domingo Suárez & 1 & & \\
\hline Fernando Martínez & 1 & & \\
\hline Fernando Velázquez & 1 & 1 & 2 \\
\hline Fortún Velázquez de Cuéllar & 2 & & 1 \\
\hline Frédulo (según Eubel) & 2 & & 2 \\
\hline García Pérez & 1 & & 4 \\
\hline Juan del Campo & 1 & & 1 \\
\hline Juan Martínez Contreras & 1 & & \\
\hline Martín & 1 & & \\
\hline Martín Fernández & 1 & & \\
\hline Melendo Pérez & 1 & & \\
\hline Nicolás de Viedma & 1 & & \\
\hline Pascual & 1 & & \\
\hline Pedro Lorenzo & 1 & & \\
\hline Raimundo & 1 & & \\
\hline Rodrigo Sánchez de Arévalo & 1 & & \\
\hline Rodrigo Vázquez & 1 & & \\
\hline Sancho & 1 & & \\
\hline Sancho de Rojas & 1 & & \\
\hline & 1 & & \\
\hline
\end{tabular}

\section{BIBLIOGRAFÍA CITADA}

Álvarez Palenzuela, Vicente Ángel (2010), Colección documental del Archivo de la Catedral de León. Actas capitulares III (1460-1469), León, Centro de Estudios e Investigación San Isidoro.

Alvira Cabrer, Martín (20s1), Entre Alfonso X el Sabio y Jean de Joinville: el embajador García Pérez (1252-1267), en Nieto Soria, José Manuel; Villarroel González, Óscar (coords.), El embajador: evolución en la Edad Media peninsular, Gijón, Trea, pp. 59-96. 
Autrand, François (1999), Gontier Col, un conseiller diplomatique de Charles VI, en Arras et la diplomatie européenne XVe-XVIe siècles, Arras, Artois Presses Universitaires, pp. 27-45.

Ayala Martínez, Carlos de (1987), Alfonso X: Beaucaire y el fin de la pretensión imperial, "Hispania" 47/165, pp. 5-31.

Ayala Martínez, Carlos de (2014-2015), La política eclesiástica de Alfonso X. El rey y sus obispos, "Alcanate" 9, pp. 41-105.

Azcona, Tarsicio de (1960), La elección y reforma del episcopado español en tiempo de los Reyes Católicos, Madrid, CSIC.

Ballesteros Beretta, Antonio (1918), Alfonso X, emperador (electo) de Alemania, Madrid, Real Academia de la Historia.

Beceiro Pita, Isabel (1995-1996), La tendencia a la especialización de funciones en los agentes diplomáticos entre Portugal y Aragón (14121465), en El poder real en la Corona de Aragón (siglos XIV-XVI). Actas del XV Congreso de Historia de la Corona de Aragón (Jaca, 20-25 de septiembre de 1993), vol. II, Zaragoza, Diputación General de Aragón, pp. 441-455.

Beltrán de Heredia, Vicente (1966), Bulario de la Universidad de Salamanca, Salamanca, Editorial Universidad de Salamanca.

Beltrán de Heredia, Vicente (1970), Cartulario de la Universidad de Salamanca, Salamanca, Editorial Universidad de Salamanca.

Benito Ruano, Eloy (1960), Toledo en el siglo XV. Vida política, Madrid, CSIC. Beolchini, Valeria; García de Cortázar, José Ángel; Pavón, Marta (2011), Documentación Medieval referente a Cantabria en el Archivo Secreto Vaticano (1209-1484), Santander, Fundación Botín.

Bofarull y Sans, Francisco de Asís de (1882), Felipe de Malla y el Concilio de Constanza. Estudio histórico-biográfico; documentos justificativos, y correspondencia diplomática de los embajadores aragoneses, Gerona, Paciano Torres.

Böhmer, Johann Friedrich; Ficker, Julius; Winkelmann, Eduard (1881-1901), Regesta Imperii V. Jüngere Staufer 1198-1272. Die Regesten des Kaiserreichs unter Philipp, Otto IV, Friedrich II, Heinrich (VII), Conrad IV, Heinrich Raspe, Wilhelm und Richard. 1198-1272, Innsbruck, Wagner'schen Universität.

Bombi, Barbara (2017), Anglo-Papal Relations in the Early Fourteenth Century: A Study in Medieval Diplomacy, Oxford, Oxford University Press.

Cal Pardo, Enrique (1999), Colección diplomática medieval do Arquivo da Catedral de Mondoñedo, Santiago de Compostela, Consello da Cultura Galega.

Cañas Gálvez, Francisco de Paula (2019), Ordoño Rodríguez de Villaquirán: Un procurador de la curia de Gil de Albornoz en la corte pontificia 
de Aviñón (1338-†1348), en Vigil Montes, Néstor (coord.), Comunicación política y diplomacia en la Baja Edad Media, Évora, Publicações do CIDEHUS, pp. 26-46.

Carriazo Rubio, Juan Luis (2021), Alvar García de Illas: servicios diplomáticos y aspiraciones señoriales bajo el reinado de Alfonso XI de Castilla, "En la España Medieval" 44 (en prensa).

Cavero Domínguez, Gregoria (2018), Martín Fernández, un obispo leonés del siglo XIII. Poder y gobierno, Madrid, La Ergástula.

Cendón Fernández, Marta (1995), El sepulcro del arzobispo don Álvaro de Isorna en la catedral de Santiago, "Cuadernos de estudios gallegos" 42/107, pp. 209-226.

Cherubini, Paolo (ed.) (1997), Iacopo Ammannati Piccolomini. Lettere (1441479), Roma, Ministero per i beni culturali e ambientali.

Cingolani, Stefano M.; Villarroel González, Óscar (2021), La importancia del embajador: cambios de personal y la negociación de Alfonso $V$ con Castilla (1417-1418), en Nieto Soria, José Manuel; Villarroel González, Óscar (coords.), El embajador: evolución en la Edad Media peninsular, Gijón, Trea (en prensa).

Crónica de Alfonso XI, ed. Cayetano Rosell, Madrid, Rivadeneyra, 1875.

Cuella Esteban, Ovidio (2009), Bulario de Benedicto XIII. IV. El papa Luna (1394-1423), promotor de la religiosidad hispana, Zaragoza, Institución Fernando el Católico.

Cuella Esteban, Ovidio (2011), Bulario de Benedicto XIII (1394-1423). I La Curia caesaraugustana. II Grupos privilegiados: servidores del papa y del rey, Zaragoza, Institución Fernando el Católico.

Daumet, Georges (1898), Étude sur l'alliance de la France et la Castille au $X I V^{e}$ et au $X V^{e}$ siècles, París, Bouillon.

Daumet, Georges (1913), Mémoire sur les relations de la France et de la Castille de 1255 à 1320, París, Fontemoing.

Delle Donne, Fulvio (2004), Politica e letteratura nel mezzogiorno medievale, Salerno, Carlone editore.

Diago Hernando, Máximo (1991), Los Velázquez de Cuéllar, tenentes de Arévalo, en el horizonte político a fines de la Edad Media, "Cuadernos Abulenses" 16, pp. 11-40.

Diago Hernando, Máximo (2009), El Contador Mayor Juan Velázquez de Cuéllar: ascenso y caída de un influyente cortesano en la Castilla de comienzos del siglo XVI, "Cuadernos de Historia de España" 83, pp. 157-186.

Díaz Ibáñez, Jorge (2015), El arzobispo Alfonso Carrillo de Acuña (14121482). Una revisión historiográfica, "Medievalismo: Boletín de la Sociedad Española de Estudios Medievales" 25, pp. 135-196. 
Díaz Martín, Luis Vicente (1987), Castilla 1280-1360: ¿Política exterior o relaciones accidentales?, en Génesis medieval del Estado moderno en Castilla y Navarra (1250-1380), Valladolid, Ámbito, pp. 125-147.

Díaz Martín, Luis Vicente (1988), Los inicios de la politica internacional de Castilla (1360-1410), en Rucquoi, Adeline (coord.), Realidad e imágenes del poder. España a fines de la Edad Media, Valladolid, Ámbito, pp. 57-83.

Domínguez Sánchez, Santiago (1996), Documentos de Clemente IV (12651268) referentes a España, León, Universidad de León.

Domínguez Sánchez, Santiago (1997), Documentos de Gregorio X (12721276) referentes a España, León, Universidad de León.

Domínguez Sánchez, Santiago (2003), Documentos pontificios referentes a la Diócesis de León (siglos XI-XIII), León, Universidad de León.

Domínguez Sánchez, Santiago (2007), Los procuradores de los reinos hispanos ante la Curia romana en el siglo XIII, León, Universidad de León.

Favier, Jean (1966), Les finances pontificales à l'époque du Grand Schisme d'Occident 1378-1409, París, Boccard.

Fernández Alonso, Justo (1963), Legaciones y nunciaturas en España, Roma, Instituto Español de Historia Eclesiástica.

Fernández Gallardo, Luis (2002), Alonso de Cartagena (1385-1456). Una biografía politica en la Castilla del siglo XV, Valladolid, Junta de Castilla y León.

Fernández-Viagas Escudero (2017), El rey en las Partidas de Alfonso X: su vicariato divino y su caracterización bajo esquemas de sacralidad, "Hispania Sacra" 69/139, pp. 61-80.

Franco Silva, Alfonso (1997), La provisión del Maestrazgo de Santiago tras la muerte de Juan Pacheco. Unas cartas inéditas, en Actas III Jornadas Hispano-portuguesas de Historia Medieval. La Península Ibérica en la Era de los Descubrimientos (1391-1492), Sevilla, Consejería de Cultura, pp. 561-583.

Galíndez de Carvajal, Lorenzo, Crónica del serenísimo príncipe don Juan II de Castilla: Crónicas de los Reyes de Castilla, ed. Cayetano Rosell, Madrid, Biblioteca de Autores Españoles, 1953.

García de Santa María, Alvar, Crónica de don Juan II de Castilla (1420-1434), Madrid, Marco y Viñas, 1891 (Documentos Inéditos para la Historia de España, 99-100).

García Isaac, José Marcos (2020), Acción diplomática e itinerario de una embajada aragonesa a Enrique $V$ de Inglaterra previa a la batalla de Agincourt (1415), en Nieto Soria, José Manuel; Villarroel González, Óscar (coords.), Diplomacia y cultura política en la península ibérica (siglos XI al XV), Madrid, Sílex Ediciones, pp. 271-289. 
Gaudemet, Jean (1986), Un point de rencontre entre les pouvoirs politiques et l'Église: le choix des évêques (schéma pour une enquête), en Genet, Jean-Philippe, État et église dans la genèse de l'état moderne: actes du colloque organisé par le Centre National de la Recherche Scientifique et la Casa de Velázquez; Madrid, 30 novembre et $1^{\text {er }}$ décembre 1984, Madrid, Casa de Velázquez, pp. 279-293.

Genet, Jean-Philippe (1986), État et église dans la genèse de l'état moderne: actes du colloque organisé par le Centre National de la Recherche Scientifique et la Casa de Velázquez; Madrid, 30 novembre et $1^{\text {er }}$ décembre 1984, Madrid, Casa de Velázquez.

Gil Ortega, Carmen (2015), Alfonso Carrillo de Acuña (1413-1482), un arzobispo proconverso en la Castilla del siglo XV, "eHumanista/Conversos" 3, pp. 138-155.

González Jiménez, Manuel (2004), Alfonso X el Sabio, Barcelona, Ariel.

González Nieto, Diego (2018), El pontificado y la Guerra Civil castellana (14651468): la búsqueda de la legitimidad pontificia, "Ab Initio" 12, pp. 3-22.

González Nieto, Diego (2019), Los agentes diplomáticos en la Curia pontificia de Enrique IV, rey de Castilla (1454-1474): perfil socio-profesional, "eHumanista" 43, pp. 107-125.

González Rolán, Tomás; Saquero Suárez-Somonte, Pilar (2010), Los comienzos de la diplomacia moderna en Castilla: Alfonso de Cartagena (1385-1456), "La Corónica" 39-1, pp. 147-160.

Gran Crónica de Alfonso XI, ed. Diego Catalán, Madrid, Gredos, 1977.

Grevin, Benoît (2008), The Rethorical Mysteries of the Medieval State: The Writing of Power in Western Europe (Thirteenth to Fifteenth Centuries), "Annales, Histoire, Sciences Sociales" 63/2, pp. 271-300.

Grevin, Benoît (2020), Al di là delle fonti “classiche”. Le epistole dantesche e la prassi duecentesca dell'ars dictaminis, Venecia, Edizione Ca'Foscari.

Hernández, Francisco; Linehan, Peter (2004), The Mozarabic Cardinal: the Life and Times of Gonzalo Pérez Gudiel, Florencia, Sismel Edizioni del Galluzzo.

Linehan, Peter E. (1975), La Iglesia española y el papado en el siglo XIII, Salamanca, Universidad Pontificia.

Linehan, Peter E. (1979), Proctors representing Spanish interests at the papal court, 1216-1313, "Archivum Historiae Pontificiae” 17, pp. 69-123.

Linehan, Peter E. (1980), Spanish litigants and their agents at the $13^{\text {th }}$ century Papal Curia, en Kjutiner, Stephan; Pennington, Kenneth, Proceedings of the fifth International Congress of Medieval Canon Law. Salamanca, 21-25 September 1976, Ciudad del Vaticano, Biblioteca Apostólica Vaticana, pp. 487-501. 
López, Atanasio (1943), El franciscanismo en España durante los pontificados de Calixto III, Pío II y Paulo II a la luz de los documentos vaticanos: Examen del «Bullarium Franciscanum», "Archivo IberoAmericano" 3, pp. 496-570.

López Fonseca, Antonio; Ruiz Vila, José Manuel (2014), Rodrigo Sánchez de Arévalo, un humanista al servicio de la corona y el papado, "Anuario de Historia de la Iglesia" 23, pp. 323-332.

López Fonseca, Antonio; Ruiz Vila, José Manuel (2015), Rodrigo Sánchez de Arévalo: un ensayo bibliográfico, "Tempus: Revista de Actualización Científica sobre el Mundo Clásico en España” 37, pp. 41-63.

Marías, Fernando; Serra, Amadeo (2005), La capilla Albornoz de la catedral de Toledo y los enterramientos monumentales de la España bajomedieval, en Guillaume, Jean (dir.), Demeures d'éternité. Églises et chapelles funéraires aux XVe et XVI siècles, París, Picard, pp. 33-48.

Meserve, Margaret; Simonetta, Marcello (2004), Pius II Commentaries, Cambridge, Harvard University Press.

Mirecki, Guillermo (1991), Apuntes genealógicos y biográficos de don Alfonso Carrillo de Acuña, arzobispo de Toledo, "Anales Toledanos" 28, pp. 55-76.

Moeglin, Jean-Marie; Péquignot, Stéphane (2017), Diplomatie et "relations internationales" au Moyen Âge (IX-XV siècles), París, Presses Universitaires de France.

Morelló Baget, Jordi (2013), Financiar el reino terrenal. La contribución de la Iglesia a finales de la Edad Media (siglos XIII-XVI), Barcelona, CSIC - Institución Milà i Fontanals.

Moreno Hernández, Carlos (1985), Pero Guillén de Segovia y el círculo de Alfonso Carrillo, "Revista de Literatura" 47, pp. 17-49.

Moxó, Salvador de (1975), La promoción política y social de los «letrados» en la Corte de Alfonso XI, "Hispania" 35, pp. 5-29.

Nieto Soria, José Manuel (1988), Iglesia y poder real en Castilla: el episcopado 1250-1350, Madrid, Universidad Complutense.

Nieto Soria, José Manuel (1993a), Ceremonias de la realeza. Propaganda y legitimación en la Castilla trastámara, Hondarribia, Nerea.

Nieto Soria, José Manuel (1993b), Iglesia y génesis del Estado moderno en Castilla (1369-1480), Madrid, Universidad Complutense.

Nieto Soria, José Manuel (1994), El pontificado de Martín V y la ampliación de la soberanía real sobre la iglesia castellana (1417-1431), "En la España Medieval" 17, pp. 113-132.

Nieto Soria, José Manuel (1996), Enrique IV y el pontificado (1454-1474), "En la España Medieval" 19, pp. 167-238.

Nieto Soria, José Manuel (2004), Dinero y política en torno a una vacante episcopal. La provisión de Toledo en 1442, en Díaz y Díaz, Manuel 
Cecilio; Díaz de Bustamante, Mercedes; Domínguez García, Manuela, Escritos dedicados a José María Fernández Catón, vol. II, León, Centro de Estudios San Isidoro, pp. 1059-1071.

Nieto Soria, José Manuel (2009), La dimensión cultural de la diplomacia castellano-leonesa en la época Trastámara, en El intercambio artístico entre los reinos hispanos y las cortes europeas en la Baja Edad Media, León, Universidad de León, pp. 15-28.

O'Callaghan, Joseph F. (1993), The Learned King: the Reign of Alfonso X of Castile, Filadelfia, University of Pennsylvania Press.

Ochoa Brun, Miguel Ángel (1991), Historia de la diplomacia española, vol. I, Madrid, Ministerio de Asuntos Exteriores.

Palencia, Alonso de, Gesta hispaniensia ex annalibus suorum dierum collecta, ed. Bryan Tate, Jeremy Lawrence, Madrid, Real Academia, 1998.

Pedretti, Marco (2012), A Catalan Diplomat, Theologian and Preacher at the Council of Constance: Master Felipe de Malla, "Revue des sciences religieuses" 86/2, pp. 143-161.

Potthast, August (1874-1875), Regesta pontificum Romanorum, Berlín, Veit.

Risco, Manuel (1794), España sagrada, vol. XXXVIII, Madrid, Blas Román.

Rodríguez R. de Lama, Ildefonso (1976), La documentación pontificia de Alejandro IV (1254-1261), Roma, Instituto Español de Historia Eclesiástica.

Rodríguez R. de Lama, Ildefonso (1981), La documentación pontificia de Urbano IV (1261-1264), Roma, Instituto Español de Historia Eclesiástica.

Ruiz Vila, José Manuel (2009), Rodrigo Sánchez de Arévalo: un hombre del Renacimiento, "Torre de los Lujanes: Boletín de la Real Sociedad Económica Matritense de Amigos del País" 65, pp. 125-138.

Santos Lasúrtegui, Alfonso de los (1935), La Hermandad de Guipúzcoa y el corregidor doctor Gonzalo Moro, San Sebastián, Leizaola.

Schaller, Hans Martin (1958), Die Kanzlei Kaiser Friedrichs II. Ihr Personal und ihr Sprachstil. Erster Teil, "Archiv für Diplomatik, Siegel und Wappenkunde" 4, pp. 264-327.

Serra Estellés, Xavier (2010), El Cisma de Occidente y la Asamblea de Medina del Campo de 1380-1381 en el Ms. lat. 11745 de la Biblioteca Nacional de Francia, "Anthologica Annua" 57, pp. 33-303.

Serrano, Luciano (1915), Alfonso XI y el Papa Clemente VI durante el cerco de Algeciras, "Cuadernos de trabajos de la Escuela Española de Arqueología é Historia en Roma", pp. 1-35.

Suárez Bilbao, Fernando (1994), Enrique III (1390-1406), Palencia, La Olmeda.

Suárez Fernández, Luis (1960), Castilla, el Cisma y la crisis conciliar (13781440), Madrid, CSIC. 
Torremocha Silva, Antonio (1994), Algeciras entre la Cristiandad y el Islam, Algeciras, Instituto de Estudios Campogibraltareños.

Trenchs Odena, Josep (1980), La comitiva de Alfonso XI: notas para su estudio, "Saitabi" 30, pp. 11-20.

Tuchman, Barbara W. (2014), Un espejo lejano: el calamitoso siglo XIV, Barcelona, Ariel.

Vázquez Núñez, Guillermo (1931), Manual de Historia de la Orden de Nuestra Señora de la Merced, Toledo, Editorial Católica Toledana.

Velázquez Campo, Lorenzo (1997), Rodrigo Sánchez de Arévalo, en Fartos Martínez, Maximiliano (coord.), La filosofía española en Castilla y León: de los orígenes al Siglo de Oro, Valladolid, Universidad de Valladolid, pp. 121-136.

Verger, Jacques (1999), Gentes del saber en la Europa de finales de la Edad Media, Madrid, Editorial Complutense.

Villarroel González, Óscar (2003a), Las elecciones episcopales en la primera mitad del siglo $X V$. Realidad y representación de la «libertas» eclesiástica, en Jiménez Alcázar, Juan Francisco; Eiroa Rodríguez, Jorge; Ortuño Molina, Jorge (eds.), Actas del I Simposio de Jóvenes Medievalistas. Lorca 2002, Murcia, Universidad de Murcia - Ayuntamiento de Lorca - Academia Alfonso X el Sabio - Fundación Cajamurcia, pp. 261-273.

Villarroel González, Óscar (2003b), Las relaciones entre la monarquía y los arzobispos de Toledo en época de Juan II de Castilla, Toledo, Ayuntamiento de Toledo.

Villarroel González, Óscar (2007), Castilla y el Concilio de Siena (14231424): la embajada regia y su actuación, "En la España Medieval" 30, pp. 131-172.

Villarroel González, Óscar (2010a), Eclesiásticos en la diplomacia castellana en el siglo XV, "Anuario de Estudios Medievales" 40/2, pp. 791-819.

Villarroel González, Óscar (2010b), El rey y el papa. Política y diplomacia en los albores del Renacimiento (Castilla en el siglo XV), Madrid, Sílex Ediciones.

Villarroel González, Óscar (2011), El rey y la Iglesia castellana. Relaciones de poder con Juan II (1406-1454), Madrid, Fundación Ramón Areces.

Villarroel González, Óscar (2013a), Eclesiásticos en la negociación de la paz en la Castilla bajomedieval, en Arranz Guzmán, Ana; Rábade Obradó, María del Pilar; Villarroel González, Óscar, Guerra y paz en la Edad Media, Madrid, Sílex Ediciones, pp. 304-341.

Villarroel González, Óscar (2013b), La tributación de los eclesiásticos castellanos en el siglo XV: entre el rey y el papa, en Morelló Baget, Jordi 
(ed.), Financiar el reino terrenal. La contribución de la Iglesia a finales de la Edad Media (siglos XIII-XVI), Barcelona, CSIC - Institución Milà i Fontanals, pp. 315-343.

Villarroel González, Óscar (2014), Papado y monarquía: los poderes imbricados, en Pena González, Miguel Anxo; Rodríguez-San Pedro Bezares, Luis Enrique (coords.), La Universidad de Salamanca y el pontificado en la Edad Media, Salamanca, Universidad Pontificia de Salamanca, pp. 89-107.

Villarroel González, Óscar (2016a), Autoridad, legitimidad y honor en la diplomacia: los conflictos anglo-castellanos en los concilios del siglo XV, "Espacio, Tiempo y Forma. Serie III. Historia Medieval" 29, pp. 777-813.

Villarroel González, Óscar (2016b), Formación para el servicio del rey y de la Iglesia en la Castilla bajomedieval, en Sabaté, Flocel (dir.), La formació de la personalitat a l'Edat Mitjana, Balaguer, Editorial Pagès, pp. 131-149.

Villarroel González, Óscar (2016c), Juan Martínez Contreras: el ascenso de un clérigo menor y el servicio regio, en Vasconcelos Vilar, Herminia; Branco, Maria João (dirs.), Ecclesiastics and political state building in the iberian monarchies, $13^{\text {th }}-15^{\text {th }}$ centuries, Évora, Publicações do Cidehus, pp. 183-200.

VIllarroel González, Óscar (2017), Álvaro Núñez de Isorna: un prelado y el poder, "Edad Media. Revista de Historia" 18, pp. 263-292.

Villarroel González, Óscar (2018), La formación de los diplomáticos en la Castilla bajomedieval, "Studia Histórica. Historia Medieval" 36/2, pp. 114-146.

Villarroel González, Óscar (2019a), Comunicar y negociar por el rey: los eclesiásticos al frente de embajadas en la diplomacia castellana (siglos XIII al XV), en Vigil Montes, Néstor (dir.), Comunicación política y diplomacia en la Baja Edad Media, Évora, Publicações do CIDEHUS, pp. 240-278.

Villarroel González, Óscar (2019b), Fernando de Illescas: los servicios diplomáticos de un fraile castellano, en Chelle Ortega, José Antonio; García Isaac, José Marcos; Villarroel González, Óscar (coords.), Entre el cielo y la tierra. El papel de los eclesiásticos en los círculos de poder en los reinos ibéricos (1369-1504), Madrid, La Ergástula, pp. 131-150.

Villarroel González, Óscar (2020), Juan Hurtado de Mendoza, señor de Almazán, un noble embajador castellano, en Carceller Cerviño, María Pilar; Nieto Soria, José Manuel (coords.), La nobleza y la cultura política de la negociación en la baja Edad Media, Madrid, Sílex Ediciones, pp. 189-220. 
Weiß, Steffan (2016), The Curia: Camera, en Sisson, Keith; Larson, Atria A. (eds.), A Companion to the Medieval Papacy, Leiden, Brill, pp. $220-238$.

Williman, Daniel (1988), The Right of Spoil of the Popes of Avignon: 13161415, Filadelfia, American Philosophical Society.

Zunzunegui Aramburu, José (1960), La misión del obispo de Senez al reino de Castilla (1354-1355), "Anthologica Annua" 8, pp. 11-42.

Zurita, Jerónimo (2003), Anales de la Corona de Aragón, ed. Ángel Canellas López, Zaragoza, Institución Fernando el Católico [en línea], https://ifc.dpz.es/publicaciones/ver/id/2448 [consulta: 13/06/2020].

Fecha de recepción del artículo: julio 2020

Fecha de aceptación y versión final: marzo 2021 